\title{
GARANTISMO Y ESTADO CONSTITUCIONAL EN LA CONSTITUCIÓN DEL ECUADOR PARA EL SIGLO XXI. A PROPÓSITO DE PRINCIPIA IURIS
}

\author{
Garantism and Constitutional State in Ecuador's Constitution \\ for 21st Century. A read of Principia iuris
}

\author{
Luis Fernando ÁVILA LINZÁN
}

\begin{abstract}
Sumario:
I. Introducción: II. Ferrajoli, el neoconstitucionalismo y el proceso constituyente. III. La semántica: el orden y clasificación de los derechos. IV. La pragmática: las garantías y la democracia sustancial. V. La sintáctica: el proyecto de transformación constitucional. VI. Conclusiones. El garantismo como horizonte. VII. Fuentes.
\end{abstract}

Resumen: El presente ensayo busca aplicar las categorías de la teoría axiomatizada a la experiencia del discurso del garantismo y el Estado constitucional en el proceso constituyente ecuatoriano de 2007 que permitió la promulgación de la Constitución de 2008. Con este fin, en una primera parte, se explica la recepción local de la teoría de Luigi Ferrajoli durante el proceso constituyente del Ecuador. Luego se desarrolla el problema del lenguaje al momento de estructurar los derechos, en tanto objeto teórico del garantismo; para, posteriormente, analizar las diversas opciones teóricas para la construcción del garantismo, denominado aquí "nivel de agencia política". Finalmente se intenta explicar la proyección política del garantismo. La tesis central del autor es que la teoría axiomatizada del Derecho es útil, también, para el análisis político estructural.

Palabras Clave: Garantismo. Estado Constitucional. Nuevo Constitucionalismo Latinoamericano. Teoría Jurídica Crítica, Ecuador.

Abstract: This essay aims at applying the categories of an axiomatic theory of law to the experience derived from 'garantism' and constitutional state discourses in the context of 2007 Ecuadorian Constitution-making process, which allowed the enactment of the Constitution in 2008. To this end, first of all, an explanation of the local reception of Luigi Ferrajoli's theory during the constitution-making process in Ecuador is offered. After developing the problem of language when structuring rights (which are the subject matter of the 'garantism'), this paper analyzes the range of theoretical options for the construction of 'garantism', in other words: the 'level of political agency'. Finally this work attemps to explain the political importance of the 'garantism'. The autor's point is than an axiomatic theory of law is also useful for structural policy analysis.

\footnotetext{
${ }^{1}$ Profesor de lnstituto de Altos Estudios Nacionales del Ecuador, Universidad Andina Simón Bolívar de Quito y de la Universidad de Especialidades Espíritu Santo en materias relacionadas con Derecho Constitucional y Derechos Humanos. Ex Coordinador de la Relatoría de la Corte Constitucional de Ecuador y Secretario Ejecutivo de la Red por el Constitucionalismo Democrático (RCD). Contacto: ecuadorconstitucional@yahoo. com
} 
Keywords: Garantism. Constitutional State. New Latin-American Constitutionalism. Critical Legal Thinking. Ecuador.

La democracia implica necesariamente el derecho. Bien puede haber, ciertamente, derecho sin democracia. Pero no puede haber democracia sin derecho [...] Ésa es, por lo demás, una dura lección de la historia, que nos ha enseñado que los valores principales que las razones principales de todos los fracasos de las grandes esperanzas suscitadas por las revoluciones del siglo pasado, aun animados por proyectos de emancipación universal, han sido el total desprecio del derecho y de los derechos y la ingenua confianza en un poder 'bueno' sólo por haber sido conquistado y ejercido en nombre de los oprimidos.

L. Ferrajoli

\section{INTRODUCCIÓN}

Cuando leí el libro de Luigi Ferrajoli Principia iuris. Teoría del Derecho y de la Democraciasinceramente, sólo algunas partes- motivo de este trabajo, tuve dos impresiones. La primera es que este libro es un trabajo que codifica gran parte del trabajo realizado por el maestro, y la segunda es que, sin embargo, encuentro algunos aspectos nuevos. Por supuesto, no soy un versado lector de su obra, pues he conocido apenas aquello que me ha sido instrumental para las luchas desde el derecho y, debo admitir, que lo he hecho con bastante desorden y poca sistematicidad. Sólo en esta ocasión, y con motivo de un libro en su honor, me he planteado leer con mayor detenimiento su pensamiento desde Principia iuris. La obra, por cierto, es de difícil acceso para estudiantes de Derecho y gente común. Su costo es una barrera en un país que ha estructurado el poder de unos pocos desde el desgobierno en la educación y su acomodo al mercantilismo de quienes venden libros como una mercancía más. Posiblemente, esto ocurre en otros países de la Región, pero en Ecuador aquello va de la mano de un débil hábito de lectura en la población, particularmente en el gremio de abogadas/os.

Resulta curioso, por ejemplo, que en Ecuador no exista una edición nacional de la Teoría Pura del Derecho de Kelsen. Ni siquiera hay un estudio sistemático de su obra más allá del trabajo citado. Sirvió Kelsen, y más concretamente la famosa pirámide del ordenamiento jurídico, como un recurso didáctico para dar a las/os estudiantes una visión panorámica del derecho. Cuando ingresé a la facultad de Derecho en 1997, todas/os las/os profesoras/es decían ser kelsenianos y convencidos positivistas. Nadie, por supuesto, había leído ni siquiera Teoría Pura del Derecho, mucho menos nosotros, pues la educación jurídica consistió en el análisis desconectado de varias doctrinas, el aprendizaje de un casuismo rupestre (yo tuve

\footnotetext{
${ }^{2}$ FERRAJOLI, Luigi, Principia iuris. Teoría del Derecho y de la Democracia, tomo II: Teoría de la Democracia, Madrid, Editorial Trotta, 2011, p. 17. Para efectos de analizar esta obra, vamos a considerar cada tomo como un texto independiente, aunque se rompa la lógica uniforme de citación de este ensayo.
} 
un caso, decían nuestros maestras/os) y el adiestramiento en las reglas informales que rigen el proceso judicial.

A la obra de Ferrajoli le sucede lo mismo, su lectura es frugal y hasta deformada. Se le atribuye desde el proceso constituyente -como se verá más adelante- significados diversos y dentro del discurso del neoconstitucionalismo. Incluso, al llegar al error de pensarlo como contrario al positivismo jurídico. Cuando es todo lo contrario, un convencido positivista, pero crítico. Justamente, la obra que comento es un intento de su autor de rescatar al positivismo del embate de las múltiples corrientes iusnaturalistas y neopositivistas que lo han deformado, mediante una propuesta teórica neopositivista sistemática y estructural.

El título de esta obra es sugestivo y da continuidad a su trabajo preliminar titulado Expectativas y garantías: primeras tesis de una teoría axiomatizada del Derecho ${ }^{3}$ y anteriores trabajos advertidos por el mismo Bobbio en el prólogo del libro Derecho y razón. ${ }^{4}$ Menciona el autor que Principia iuris se entendió en el uso semántico-histórico como inicio, luego origen, y finalmente fundamento. ${ }^{5}$ Es decir, el principio fundamental y el enorme aporte del libro aquí comentado, en la línea de Bobbio, es la idea de que el derecho es una condición necesaria para la democracia: La democracia implica necesariamente el derecho. Bien puede haber, ciertamente, derecho sin democracia. Pero no puede haber democracia sin derecho. ${ }^{6}$ Este postulado es algo más que el clásico concepto de Estado de Derecho, según el cual el derecho es un límite -especialmente, las leyes- para el poder del Estado. Para el maestro, representa un salto histórico-conceptual del Estado legislativo que se funda en el principio de legalidad como norma de reconocimiento del derecho vigente, al Estado constitucional que se basa en la rígida subordinación de las leyes a los principios constitucionales como normas de reconocimiento de su validez. ${ }^{7}$

Esto ocurre, de acuerdo al maestro, porque los presupuestos de la relación entre Estado y sociedad están en crisis, pero sin que ello destruya la respuesta autónoma que puede dar el derecho; al contrario, lo obliga a la redefinición de sus clásicas categorías jurídicas, adaptándolas a las nuevas formas del poder y funciones del derecho. ${ }^{8}$ La respuesta que debe dar el derecho moderno, según esto, tampoco es nueva, pues la vemos en la obra clásica de Kelsen ¿Quién debe ser el defensor de la Constitución? en su crítica a la doctrina del pouvoir neutre de Constant y tomada por Schmitt para justificar el control constitucional por el presidente de la república. ${ }^{9}$ Según el maestro vienés: la función política de la Constitución es de poner límites jurídicos al ejercicio del poder. Garantía constitucional significa que generar seguridad de que estos límites jurídicos no serán trasgredidos. ${ }^{10}$

No obstante, el aporte central de Ferrajoli a este postulado es que la Constitución no es un texto estático ni la garantía es un fin abstracto, sino que son instrumentales y una condición en sí misma para la existencia del poder, por lo cual, el problema de la democracia

\footnotetext{
${ }^{3}$ FERRAJOLI, Luigi, “Expectativas y garantías: primeras tesis de una teoría axiomatizada del Derecho”, Doxa, núm. 20, 1997, pp. 235-278.

${ }^{4}$ FERRAJOLI, Luigi, Derecho y razón. Teoría del garantismo penal, Madrid, Editorial Trotta, 20o1, p. 14.

${ }^{5}$ FERRAJOLI, Luigi, Principia iuris. Teoría del Derecho y de la Democracia, tomo I. (Ver nota al final número 38 de este mismo tomo).

${ }^{6}$ FERRAJOLI, Luigi, Op. Cit., nota 2, p. 17.

${ }^{7}$ FERRAJOLI, Luigi, Op. Cit., nota 5, p. 4

${ }^{8}$ Ibíd.

9 SCHMITT, Karl, La Defensa de la Constitución, Madrid, Editorial Tecnos, 1998, pp. 213-224

${ }^{10}$ KELSEN, Hans, ¿Quién debe ser el defensor de la Constitución?, Madrid, Editorial Tecnos, 2002, p. 5.
} 
termina siendo no el ejercicio, sino la sustancialidad de ese ejercicio. Quiere decir esto que la Constitución es un límite en sí mismo. Consecuencia de esto, es que la teoría del derecho se torna en una precondición material para la existencia de una teoría de la democracia, entendida ésta como un límite sustancial. Al tiempo que los derechos fundamentales y las garantías son, por derivación, condiciones necesarias para la democracia. Por consiguiente, no es se trata no sólo de una teoría del garantismo, sino que la Constitución es una garantía en sí misma del derecho.

Por ello, propone Ferrajoli una teoría axiomatizada del derecho -no axiológica-, que está guiada al estudio de las formas y estructuras del ordenamiento jurídico y no necesariamente a sus contenidos normativos.

La propuesta semiótico-estructural de Ferrajoli está construida por tres partes: a) la semántica que se encarga de delimitar el objeto de la teoría, a través de las relaciones entre sus tesis y fenómenos, b) la pragmática que se refiere al campo de las opciones que intervienen en la construcción de la teoría y en la explicación de los principios que sustenta; y, c) la sintáctica que se encarga de explicar los procedimientos de formación y control que formula la teoría axiomática11. De este modo, esta propuesta pretende ser una teoría del Derecho positivo moderno y de las formas jurídicas de la democracia actual.

El presente ensayo busca aplicar las categorías lógicas de la teoría axiomatizada a la experiencia del discurso del garantismo y el Estado constitucional en el proceso constituyente ecuatoriano de 2007 que permitió la promulgación de la Constitución de 2008, considerada con justicia garantista. Con este fin voy a dividir este trabajo de la siguiente manera: (1) la primera parte titulada Ferrajoli, el neoconstitucionalismo y el proceso constituyente que, a manera de introducción, explica la recepción local de la teoría del maestro de cara al proceso constituyente del Ecuador (nivel empírico); (2) luego, la segunda parte nominada la semántica: el orden y clasificación de los derechos, desarrolla el problema del lenguaje al momento de estructural los derechos, en tanto objeto teórico del garantismo (nivel normativo); (3) a continuación, la tercera parte titulada la pragmática: las garantías y la democracia sustancial, se analizan las diversas opciones teóricas para la construcción del garantismo (nivel de agencia política); y, (4) finalmente, la sintáctica: el proyecto de transformación constitucional, que intenta explicar la proyección política del garantismo (nivel estructural). Quiero demostrar, en definitiva, que la teoría axiomatizada es útil, también, para el análisis político estructural.

\section{FERRAJOLI, EL NEOCONSTITUCIONALISMO Y EL PROCESO CONSTITUYENTE}

El Ecuador ha sido prolífico en textos constitucionales. La opinión dominante es que este fenómeno se debe a la inestabilidad política e ingobernabilidad durante toda la época republicana o a una especie de débil cultura política de la población. ${ }^{12}$ No obstante, también puede

\footnotetext{
${ }^{11}$ FERRAJOLI, Luigi, tomo I, Op. Cit., nota 5, p. 4

${ }^{12}$ Véanse los trabajos de HURTADO, Osvaldo, introd., "Los nuevos límites del estado", en El problema del estado y su reforma en América Latina, Quito, CORDES, 1989; Íd, "El sistema político en el Ecuador”, en: Ayala Mora, Enrique (ed.), Ensayos generales II: nación, estado y sistema político, Quito, Corporación Editora Nacional, 1990; Id., El poder político en el Ecuador, Quito, Planeta, Letraviva, 1993; Id., Gobernabilidad y reforma constitucional, Quito, Corporación Editora Nacional, Libros de bolsillo; vol. 8; Id., "Gobernabilidad, democracia y pobreza”, en: Zevallos, José Vicente (ed.), Estrategias para reducir la pobreza en América Latina y el Caribe, Quito, PNUD, 1997; Id., Una constitución para el futuro, Quito, Fundación Ecuatoriana de Estudios Sociales, FESO, 1998; MELMAN, Charles, Lo ingobernable en la sociedad, Corporación de Estudios 
entenderse como el resultado de una falta de acomodo de las élites que, ante la ausencia de estructuras formales para canalizar sus diferencias, despiertan de vez en cuando el perro rabioso del poder constituyente para poner orden desde el desorden. ${ }^{13}$ Prefiero pensar que esto ocurre porque existe una tendencia al activismo democrático en la población y sus élites, que se materializa en transformaciones progresistas y resistencia popular. ${ }^{14}$ Siempre más democracia, nunca menos pareciéramos pensar las/os ecuatorianas/os a lo largo de la historia. ${ }^{15}$ Por esta razón, nuestras constituciones representan el reducido espacio para asegurar las conquistas sociales, para la lucha y el debate de los problemas estructurales, y elegir nuestro destino. No quiero que estas afirmaciones se entiendan como un vacío chovinismo, sino rescatar, siguiendo el postulado teórico de Pisarello, ${ }^{16}$ la historia no contada del constitucionalismo invisibilizado por la violencia del poder brutal de las clases dominantes. Inspirado en el mismo autor y tomando su metáfora: se hace necesario denunciar el largo termidor de

para el Desarrollo; Ecuador: un problema de gobernabilidad, Seminario "Ecuador: un problema de gobernabilidad”, Quito, CORDES, 1996; SALGADO, Hernán, Manual de Justicia Constitucional Ecuatoriana, Serie Fortalecimiento de la Justicia Constitucional en el Ecuador, Corporación Editora Nacional, Quito, 2004; SALGADO PEÑAHERRERA, Germánico, "El estado ecuatoriano: crisis económica y estado desarrollista", en: Hurtado, Osvaldo, Los nuevos límites del estado, Quito, CORDES, 1989.

${ }^{13}$ ANDRADE, Pablo, "Negociando el cambio: Fuerzas Políticas en la Asamblea Constituyente ecuatoriana de 1998", en: Pablo Andrade y otros (coords.), en Estructura Constitucional en el Estado Constitucional, Quito, Universidad Andina Simón Bolívar, Fundación Centro de Estudios Políticos y Sociales y otros, 2004.

${ }^{14}$ ACOSTA, Alberto, Bitácora constituyente: ;Todo para la patria, nada para nosotros!, Quito, Abya-Yala, 2008; Id., El desarrollo en la globalización: el reto de América Latina, Caracas, ILDIS, Nueva Sociedad, 200o; Id., "El Estado plurinacional, puerta para una sociedad democrática: a manera de prólogo", en: Acosta, Alberto, comp., Plurinacionalidad: democracia en la diversidad, Quito: ABYA YALA, 2009; Id., "La Constitución de Montecrisiti, medio y fin para cambios estructurales", en Nuevas instituciones del derecho constitucional ecuatoriano, Quito, INREDH, 2009b; Id., "La cruzada contra el estado: una corriente indetenible", en: Fundación José Peralta, Reforma del Estado: propuesta popular, Encuentro: por una propuesta popular sobre reforma del estado, Quito, 1993; "Representación, participación y democracia", en Instituto Latinoamericano de Investigaciones Sociales, ILDIS, La innovación partidista de las izquierdas en América Latina, Quito, ILDIS, Fundación Friedrich Ebert, 2008; Id., "Siempre más democracia, nunca menos: a manera de prólogo", en: Acosta, Alberto, comp., El Buen Vivir: una vía para el desarrollo, Quito: Abya-Yala, 2009; Id., "Una propuesta alternativa de política y reforma estructural, Ecuador. Congreso Nacional, en coord.; Ecuador: crisis, reactivación, descentralización y cambio de modelo económico, Quito, Congreso Nacional, 1999; ÁVILA LINZÁN, Luis Fernando, Emancipación y Transformación Constitucional, Corte Constitucional, 2011; ÁVILA SANTAMARÍA, Ramiro, "Estado Constitucional de Derechos y Justicia", en Ramiro Ávila (ed.), La Constitución de 2008 en el Contexto Andino. Análisis desde la doctrina y el derecho comparado, Quito, Ministerio de Justicia, 2008; ÁVILA SANTAMARÍA, Ramiro, GRIJALVA, Agustín, y MARTÍNEZ, Rubén, (eds.), Desafíos constitucionales La Constitución ecuatoriana del 2008 en perspectiva, Ministerio de Justicia y Derechos Humanos y Tribunal Constitucional, 2008; Grijalva, Agustín, “¿Una constituyente más?”, en Revista Renovación, entre voces, ¿Qué se juega en la segunda vuelta?, núm. 4, especial Quito, nov-dic 2006; Id., "Acción Extraordinaria de Protección", en: Claudia Escobar, Teoría Práctica de la Justicia Constitucional, Quito, Ministerio de Justicia y Derechos Humanos, 2010; TRUJILLO VÁSQUEZ, Julio "El Estado en la Constitución", en: Viciano, Roberto, (ed.), Estudios sobre la constitución ecuatoriana de 1998, Valencia, CEPS, Universidad Andina Simón Bolívar, Sede Ecuador, 2005; Id., Teoría del estado en el Ecuador: estudio de derecho constitucional, Quito, Universidad Andina, 2006.

${ }^{15}$ ACOSTA, Alberto, "Siempre más democracia, nunca menos: a manera de prólogo", en: Id., (comp.), El Buen Vivir: una vía para el desarrollo, Quito: Abya-Yala, 2009.

${ }^{16}$ PISARELLO, Gerardo, Un largo termidor: historia y crítica del constitucionalismo antidemocrático, Quito, Corte Constitucional para el Período de Transición, 2011. 
un constitucionalismo en apariencia democrático que impera en el mundo, desde las experiencias democrático-participativas del Sur.

La historia conocida esconde la barbarie que la legitima, pues opera, como lo dijera Zaffaroni, como una punta de flecha ${ }^{17}$ que no se detiene y deja todo lo que se le oponga a los lados. Así, avanza el ideal del progreso sin fin dejando de lado todo aquello que ponga en cuestión socialmente naturalizada de la depredación de la naturaleza y la acumulación individual de la riqueza. Progresar significa mirar siempre hacia delante, sin detenerse a mirar los millones de muertos y estar convencidos de que mañana siempre será mejor que hoy.

Creo que el constitucionalismo de la primera década del siglo XXI tiene un potencial emancipatorio y transformador en los textos constitucionales de Bolivia (2009), Ecuador (2008) y Venezuela (1998). Al punto que, en alguna medida, nos hemos atrevido a denominar abiertamente esta corriente Nuevo Constitucionalismo Latinoamericano. ${ }^{18}$ Igual, quiero curarme de ser acusado de chovinista. En consecuencia, debo establecer los elementos que considero rompen las estructuras de patriarcalismo, exclusión y violencia social, y que le dan sentido a este constitucionalismo de nuevo cuño. Dos elementos son centrales en la reforma política de 2008: a) por una parte la búsqueda, a veces maniática, de superar la exclusión en la reestructuración de los canales institucionales de la democracia; y, b) por la otra, la apertura del espacio ciudadano para la participación democrática en los asuntos públicos. Gargarella lo resume al referirse en la siguiente cita a la Constitución del Ecuador de 2008:

[...] Es decir, hemos aprendido a reconocer, por un lado, que tiene sentido ajustarlas tuercas y tornillos de nuestra maquinaria democrática, como que tiene hacerlo de un modo favorable a la intervención cívica en política: la política -nos interesa afirmar- es nuestra, de todos, y no de un grupo , o de una clase, o de los ricos y bien nacidos de los que se hablaba en el lenguaje constitucional de hace dos siglos -en la práctica, hace no tanto tiempo-. Nuestras nuevas Constituciones son conscientes de ello y tal como la Constitución que aquí se analiza, insisten inequívocamente en la urgencia de la inclusión social, tanto como en la apertura de nuevos y mayo res espacios para el activismo ciudadano. ${ }^{19}$

Un elemento central en el proceso político de 2008 , de acuerdo a lo anterior, fue la democracia, palabra polisémica y a veces prostituida y desgastada por la demagogia de las/los políticas/os, y por la especulación y el reduccionismo de las/los académicas/os. El proceso constituyente de 2007 se fundó sobre una oposición a la democracia procedimental, al puro estilo de Schumpeter: método democrático es aquel sistema institucional, para llegar a las decisiones políticas, en que los individuos adquieren el poder de decidir por medio de una lucha de competencia por el voto del pueblo. ${ }^{20}$

Entendimos a la democracia como un espacio abierto para la participación de las/os ciudadanas/os en la toma de decisiones desde abajo. Aquello significó reemplazar la matriz

\footnotetext{
${ }^{17}$ Véase mi trabajo: ÁVILA LINZÁN, Luis Fernando, Emancipación y transformación constitucional, Corte Constitucional, 2011.

${ }^{18}$ Al respecto: VICIANO, Roberto y MARTÍNEZ, Rubén, “Aspectos Generales del Nuevo Constitucionalismo Latinoamericano”, en: Ávila Linzán, Luis Fernando, Política, Justicia y Constitución, Quito, Corte Constitucional para el período de transición, 2011; ÁVILA LINZÁN, Luis Fernando, Emancipación y transformación constitucional, cit.

${ }^{19}$ GARGARELLA, Roberto, “Presentación”, en Desafíos constitucionales la Constitución ecuatoriana del 2008 en perspectiva, Ministerio de Justicia y Derechos Humanos y Tribunal Constitucional, 2008, p. 14

${ }^{20}$ SCHUMPETER, Joseph A., Capitalismo, Socialismo y Democracia, Barcelona, Ediciones Folio, 1986, p. 343. 
ideológica de la Constitución de 1998 de la gobernabilidad ${ }^{21}$ por la de la democracia participativa. ${ }^{22} \mathrm{Y}$, al mismo tiempo, supuso otorgar al mismo proceso constituyente una legitimidad participativa. Por esta razón, se consultó al pueblo sobre si estaba de acuerdo que se realizara una Asamblea Constituyente y si aprobaba su estatuto mínimo. Luego se convocó a un proceso electoral para que el pueblo pudiera elegir a sus asambleístas. Acto seguido, la Asamblea ya instalada escuchó a amplios sectores sociales durante un año; y, finalmente, el texto decidido por las/os asambleístas se puso a consideración del mandante. El texto definitivo y aprobado popularmente entró en vigencia el 20 de noviembre de $2008 .{ }^{23}$ ¡Difícilmente, existe algún proceso parecido en el Mundo y en la historia!

Este complejo proceso político que tomó tantos resguardos democráticos fue, sin embargo, la continuación de una tendencia histórica que se hubo paulatinamente abandonado a los procesos constituyentes organizados alrededor de comisiones ad-hoc o grupos de notables. No obstante, la democratización de los procesos constituyentes comenzó cuando para el retorno de la democracia se sometió a consulta popular en 1978 el texto constitucional; y, se perfeccionó en el proceso constituyente de 1997, cuando el pueblo pudo elegir a sus delegados a la Asamblea Nacional (Asamblea Constituyente).

Justamente, este exceso de democracia llevó a la renuncia del entonces Presidente de la Asamblea Constituyente de 2007, quien proponía que era necesario más debate, por lo cual el plazo de un año fijado por el estatuto aprobado por el pueblo, sería sólo referencial. Frente a esta postura más programática (sector del socialismo programático), ganó la facción más pragmática del Movimiento Alianza País (sector del socialismo pragmático). Primó también el cálculo electoral, pues no se quiso poner en riesgo la aprobación de la Constitución por una posible prórroga ni afectar las elecciones de las autoridades que vendría inmediatamente.

Para aquel entonces, yo formaba parte del equipo de trabajo bajo la dirección de Ramiro Ávila Santamaría, subsecretario de Desarrollo Normativo del Ministerio de Justicia y Derechos Humanos (profesor de planta de la Universidad Andina Simón Bolívar de Quito), cuyo ministro era Gustavo Jalkh (entonces Presidente del Consejo de la Judicatura). Este equipo de jóvenes -una media de 30 años- trabajó para la Asamblea Constituyente los capítulos de la Constitución sobre derechos, garantía y administración de justicia. No se hicieron muchos cambios de las versiones enviadas, más bien se nutrió de otras propuestas al interior de la Asamblea. La mística de trabajo era, también, un ejercicio de democracia, pues operábamos sin horarios y mediante un liderazgo horizontal y participativo.

Sin embargo, el trabajo no fue fácil. Había que lidiar con la propia diversidad formativa e ideológica del grupo, más allá de la tutela de Ramiro. Y luchábamos contra el tiempo. ¿Qué podía dar coherencia colectiva a esta misión? Consensuamos en dos cuestiones. La primera era el énfasis en las garantías que tomamos de lo que al final de los años noventa se había nominado en América Latina neoconstitucionalismo; y, la necesidad de que la Constitución profundizara la vigencia del Estado Constitucional. De la primera cuestión se positivizó un

\footnotetext{
${ }^{21}$ HURTADO, Osvaldo, Una constitución para el futuro, Quito, Fundación Ecuatoriana de Estudios Sociales, FESO, 1998.

${ }^{22}$ ACOSTA, Alberto, "Representación, participación y democracia”, en Instituto Latinoamericano de Investigaciones Sociales, ILDIS, La innovación partidista de las izquierdas en América Latina, Quito, ILDIS, Fundación Friedrich Ebert, 2008; Id., "La Constitución de Montecrisiti, medio y fin para cambios estructurales", en Nuevas instituciones del derecho constitucional ecuatoriano, Quito, INREDH, 20o9; SANTOS, Boaventura de Sousa, "Las paradojas de nuestro tiempo y la plurinacional”, en ACOSTA, Alberto (comp.), Plurinacionalidad: democracia en la diversidad, Quito, ABYA YALA, 2009.

${ }^{23}$ Constitución del Ecuador, RO 449: 20-oct-2008.
} 
régimen de garantías en los artículos 84-86 de la Constitución (garantía normativa, garantía de la política pública y garantía jurisdiccional). El garantismo, como modelo ideológico se resume en los artículosio y 11 de nuestra Constitución Principios de Aplicación de los Derechos, mientras que el Estado constitucional se materializó en el artículo 1 del mismo cuerpo normativo: Art. 1.- El Ecuador es un Estado constitucional de derechos y justicia [la cursiva es mía], social, democrático, soberano, independiente, unitario, intercultural, plurinacional y laico. Se organiza en forma de república y se gobierna de manera descentralizada [...].

Fue allí donde conocí, a través de los libros, al profesor Luigi Ferrajoli. Leímos sobre la marcha Derechos y garantías: la ley del más débil, ${ }^{24}$ El fundamento de los derechos fundamentales, ${ }^{25}$ y Derecho y razón: teoría del garantismo penal. ${ }^{26}$ Ramiro Ávila y Agustín Grijalva habían incluidos en sus textos de cátedra el estudio de estos textos, se organizaron varios foros de discusión alrededor de sus ideas centrales y se integraron estos conceptos en las discusiones de las comisiones de la Asamblea Constituyente. Así, en medio de una pléyade de propuestas ideológicas y teóricas, intereses y solicitudes ciudadanas, el garantismo y el Estado constitucional se convirtieron en el discurso vertebrador del proceso constituyente. Trajimos por primera vez a Ecuador a Miguel Carbonell, quien había editado dos textos que habíamos leído con atención: Neoconstitucionalismo(s) ${ }^{27}$ y Teoría del neoconstitucionalis$m o .{ }^{28}$ También, habíamos devorado su libro editado y titulado Garantismo: estudios sobre el pensamiento jurídico de Luigi Ferrajoli. ${ }^{29}$ La cita de la obra de Ferrajoli en estos libros era tan profusa que llegamos a encasillar al maestro como neoconstitucionalista. Y, por añadidura, toda persona que cree en el proyecto político, conscientemente o no, inserto en la Constitución de Montecristi de 2008, se le llamó desde esa época neoconstitucionalista. Por supuesto, todo aquel que en Ecuador escriba desde sus libros o cite al profesor Ferrajoli en sus conferencias, es neconstitucionalista.

Así el garantismo - no sólo penal- y el neoconstitucionalismo se convirtieron en uno de los discursos más fuertes del proceso constituyente sobre la matriz ideológica principal de la democracia participativa. Por supuesto, fueron también importantes los discursos de género, la crítica al antropocentrismo, la doctrina de los grupos de atención prioritaria, la economía popular y solidaria, la planificación económica, la participación social, la política anticolonial y de liberación, la emancipación social, la doctrina social de la iglesia y un enorme etcétera. No obstante, este discurso fue esencial para la estructura general del texto constitucional, lo cual fue asegurado por la participación de Ramiro Ávila en la comisión ad-hoc (Comisión de Redacción de la Asamblea Constituyente) que editó el texto final de la Constitución en la Asamblea Constituyente.

Luego de aprobada la Constitución, el discurso del garantismo-neconconstitucionalismo aparece como dominante en la reflexión y enseñanza del derecho, especialmente a nivel de postgrado. Dos eran los frentes que combatía este discurso transformador en nuestra realidad ecuatoriana. El positivismo jurídico y el Estado liberal. En realidad, bajo la deno-

\footnotetext{
${ }^{24}$ FERRAJOLI, Luigi, Derechos y garantías: la ley del más débil, Madrid, Trotta, 2001.

${ }^{25}$ FERRAJOLI, Luigi, Los fundamentos de los derechos fundamentales, Madrid, Trotta, 2001.

${ }^{26}$ FERRAJOLI, Luigi,Op. Cit., nota 4, Madrid, Editorial Trotta, 2001.

${ }^{27}$ CARBONELL, Miguel (ed.), Neoconstitucionalismo(s), Madrid, Trotta, 2003.

${ }^{28}$ CARBONELL, Miguel, (ed.), Teoría del neoconstitucionalismo, Madrid, Trotta, UNAM, 2007.

${ }^{29}$ CARBONELL, Miguel y SALAZAR UGARTE, Pedro, (eds.), Garantismo. Estudios sobre el pensamiento jurídico de Luigi Ferrajoli, Madrid, Trotta-IIJ UNAM, 2005.
} 
minación de positivismo jurídico, se cobijaron varios problemas jurídicos: el normativismo, el legalismo, el formalismo y ritualismo jurídicos, y lo que Ferrajoli había llamado paleopositivismo -crítica a la razón formal ${ }^{30}$-, es decir la preeminencia del legislador en la producción de la ley. ${ }^{31}$ La discusión teórica fue dicotómica y mutuamente excluyente entre neoconstitucionalismo y positivismo jurídico. Incluso, se puso en el mismo saco al positivismo normativista kelseniano que pugna con la realidad del Derecho ecuatoriano -posiblemente, de gran parte de América Latina-.

Bobbio, por ejemplo, postulaba que gran parte de la experiencia jurídica de las personas era normativa, por lo cual su teoría propuesta era normativista o de análisis normativo. Sin embargo, el mismo autor no sólo creía que el orden normativo no se agotaba en las normas jurídicas, las cuales eran sólo parte de aquel, sino que, tampoco, lo hacía en las normas positivas. Existen normas religiosas, culturales de toda índole que rigen la conducta humana, y ciertos programas individuales de acción para la dirección de la propia vida. Nos referimos en Ecuador al positivismo, en mi criterio, al fenómeno de un formalismo legal más rudimentario y de origen castellano y práctica colonial, según el cual la/el operadora/r jurídica/o se rige estrictamente a lo establecido en la ley. Ilustremos esto con el siguiente paisaje de un día normal en un juzgado ecuatoriano: un juez ha devuelto una demanda para que se corrija la nominación de su cargo. No debe decir juez de lo civil de Pichincha, sino juez de lo civil del cantón Quito. Devuelve una vez más el escrito, por otra razón formal... Y, finalmente, niega la demanda porque el contrato de corretaje no es un contrato nominado en el Código Civil o Código de Comercio, cuando en realidad es prestación de servicios con comisión, y cuando el principio del derecho civil reza que todo lo que no está prohibido en la ley está permitido. Esta forma local del positivismo tiene raíces profundas en la forma escrita del sistema judicial que es un problema de eficacia judicial y no de normatividad; es un problema de cultura jurídica y no teoría del derecho.

De acuerdo a esta dicotomía neoconstitucionalismo-positivismo, no se discriminó la existencia de varios tipos de positivismo jurídico ni se reflexionó sobre el vacío sistémico del neoconstitucionalismo. Carbonell ha admitido que se trata de una teoría en construcción, pero que, sin embargo, en la región presenta cierto desarrollo doctrinal y constituciones materiales a través de un sistema de garantías, prácticas concretas de intervención del Estado en pro de los derechos y una jurisprudencia progresista. ${ }^{32}$ Se juntó como elementos centrales de este discurso a las ideas de los autores que comparecieron a los libros editados por Carbonell, el rol activista del juez en la creación del derecho y su intervención en las políticas públicas, y el Estado constitucional como un paradigma para superar al Estado liberal. ${ }^{33} \mathrm{Al}$ mismo tiempo, se traslapó un debate europeo que nada tiene que con el neoconstitucionalismo latinoamericano. Me refiero a si las nuevas formas constitucionales, especialmente, la emergencia del principalismo jurídico y los organismos de control y garantía constitucional en Europa, permiten una nueva relación entre moral y derecho, lo cual parecía un evento

\footnotetext{
${ }^{30}$ FERRAJOLI, Luigi, Op. Cit., nota 24, p. 20-22.

${ }^{31}$ RENTERÍA, Adrian, “Justicia constitucional y la esfera de lo indecible en Luigi Ferrajoli”, Isonomía, núm. 18,2003 , p. 245.

${ }^{32}$ CARBONELL, Miguel, El neoconstitucionalismo en América Latina: elementos para una definición, México, Instituto de Investigación Jurídica-UNAM, 2008.

33 ÁVILA SANTAMARIA, Ramiro, "Neoconstitucionalismo transformador. El Estado y el Derecho", en: Alberto Acosta y Esperanza Martínez (comps.), ABYA YALA, Quito, 2011; Id., "El amparo constitucional: entre el diseño liberal y la práctica formal”, en Un cambio ineludible: la Corte Constitucional, Tribunal Constitucional, Quito, 2008.
} 
superado con la hegemonía del positivismo jurídico kelseniano. Nuestro neoconstitucionalismo, al contrario, hace referencia a varios temas disímiles: participación democrática, recuperación del rol económico de intervención del Estado y la distribución de la riqueza, consolidación de las garantías y el sistema de justicia en favor de la integralidad de los derechos humanos, la igualdad de los tipos de derechos, la visibilidad de grupos de atención prioritaria, consolidación de las conquistas sociales, y la preocupación por la naturaleza, la explotación de los recursos naturales y los fines del Estado. No entender esta realidad de apropiación, significación y resignificación, y recepción de la teoría del neoconstitucionalismo ha llevado a contraponerlo al positivismo de parte de los defensoras/es de la nueva Constitución, ${ }^{34}$ o creer que aquello conlleva necesariamente la construcción de un Estado socialista, judicialización de la política, autoritarismo, hiperpresidencialismo, una abierta invasión de la moral en el derecho, y una vía abierta para la arbitrariedad judicial. ${ }^{35}$

Tampoco el pensamiento de Ferrajoli guarda total relación con el discurso europeo del neoconstitucionalismo necesariamente, puesto que su obra desconfía de las posibilidades argumentativas de la justicia constitucional; porque desde el punto de vista teórico mantiene la tajante separación entre moral y derecho, ${ }^{36}$ y porque su propuesta teórica no está pensada en la preeminencia de los principios, sino de la salvaguarda de la normativa constitucional. ${ }^{37}$ Sin embargo, la teoría de Ferrajoli, al igual que nuestro neconstitucionalismo, tiene un hilo común en los debates europeos y latinoamericanos sobre el nuevo constitucionalismo, y es la fuerte crítica al mero normativismo, el cual no permite una construcción racional de las decisiones del poder, contraponiendo como antídoto el sustancialismo normativo. ${ }^{38}$

De esta manera, nuestro neconconstitucionalismo criollo con un Ferrajoli canonizado a la cabeza se convirtió en un discurso transformador, y matriz ideológica para la construcción del sistema de garantías, el Estado constitucional y la sustancialidad de los derechos en el texto constitucional de 2008, en realidad de la Constitución en sí misma. Sus principales virtudes son ser una doctrina repensada desde el sur y ser viable para estructurar y cohesionar las garantías y el Estado constitucional en la coyuntura de las reformas políticas de los años noventa y la primera década del siglo XXI. Para el mundo europeo resulta difícil entender la maraña de doctrinas y teorías, autoras/es e ideologías que se amparan bajo la denominación

34 ÁVILA SANTAMARIA, Ramiro (ed.), Neoconstitucionalismo y sociedad, Quito, Ministerio de Justicia y Derechos Humanos, 2008.

${ }^{35}$ Véanse: ECHEVERRÍA, Julio, “El Estado en la nueva Constitución”, en Santiago Andrade, Agustín Grijalva y Claudia Storini, La Nueva Constitución del Ecuador, Serie Estudios Jurídicos, Vol. 20, Quito, Corporación Editora Nacional y Universidad Andina Simón Bolívar, 2009; OYARTE, Rafael, "Relaciones Ejecutivo-Legislativo", en: Santiago Andrade, Agustín Grijalva y Claudia Storini (eds.), La nueva Constitución del Ecuador, Serie Estudios Jurídicos, Vol. 20, Quito, Corporación Editora Nacional y Universidad Andina Simón Bolívar, 2009; TORRES, Luis Fernando, “¿Cómo cambió el Ecuador entre el 2007 y el 2009?, en: Luis Fernando Torres, (ed.), Debate Constitucional. Monografías, Quito, Fundación Hans Seidel, 2010; Id., Presidencialismo Constituyente. Un camino hacia el autoritarismo en el Ecuador, Quito, Cevallos Editora Jurídica, 2009; Zaidán, Salim, “¿Neoconstitucionalismo en el Ecuador?”, en: Maldonado Muñoz, Mauricio, (ed.), Revista Ruptura, núm., 54, Quito, 2011; Id., "Peligros del empoderamiento del juez en el esquema neoconstitucional ecuatoriano”, en: Torres, Luis Fernando, (ed.), Debate constitucional con jurisprudencia, Quito, EC: Jurídica Cevallos, 2012.

${ }^{36}$ Véase: PRIETO SANCHÍS, Luis, "Principia iuris: una teoría del derecho no (neo)constitucionalista para el Estado constitucional”, Doxa, núm. 31, 2008, pp. 325-354.

${ }^{37}$ Véase: MORA SIFUENTES, Francisco M., "El garantismo como constitucionalismo de reglas. (Apuntes sobre las normas en Principia iuris”, Cuadernos electrónicos de Filosofía del Derecho, núm. 26, 2012, pp. 191-206.

${ }^{38}$ FERRAJOLI, Luigi, "Doce cuestiones en torno a principia iuris”, Revista Cultura de la Legalidad, No.1 septiembre 2011-febrero 2012, p. 7. 
de «neoconstitucionalismo». Fue, posiblemente, por este motivo que Carbonell prefiere hablar de «neoconstitucionalismos», como parte de la diversa realidad política latinoamericana. Neoconstitucionalismos que tienen mucho de positivista y de cierto relativismo teórico, y de realismo jurídico; pero que nada tiene que ver con el nuevo constitucionalismo europeo que está preocupado por la redefinición de la relación entre derecho y moral ante la crisis de certeza jurídico-política que plantean sus realidades actuales: el derrumbe paulatino del Estado de bienestar y la erosión de la institucionalidad como mecanismo de intermediación social en las sociedades europeas. A continuación, voy a utilizar las categorías generales de la teoría axiomatizada propuesta por el profesor Ferrajoli para explicar el funcionamiento y proyección de este discurso en la coyuntura del proceso constituyente.

\section{LA SEMÁNTICA: EL ORDEN Y CLASIFICACIÓN DE LOS DERECHOS}

De acuerdo al plan metodológico de Principia iuris, la semántica es la que se encarga de delimitar el objeto de la teoría, a través de las relaciones entre sus tesis y fenómenos. ${ }^{39}$ Esto tiene capital importancia para explicar la emergencia histórica del Estado constitucional, pues mientras que el Estado legislativo se funda sobre un solo ordenamiento, con al menos, un nivel normativo; el Estado constitucional permite que existan varios presupuestos metateóricos de aplicación operativa del derecho. De esta manera, en el Estado Constitucional coexisten necesariamente varios niveles complejos que exigen normas metateóricos deóntico reguladores y la participación de más actores que el intérprete normativo (legislador). Así, por ejemplo, si en el derecho legislativo las antinomias y lagunas son llenadas a través de los principios de temporalidad y especialidad; en el derecho constitucional, lo son mediante el principio de jerarquía. Una metateoría de la semántica requiere que se relacionen los enfoques normativista y realista, el deber y el ser para determinar el derecho legítimo o el derecho válido. ${ }^{40}$

A partir de esto, la formulación teórica es vital, también, para la reformulación del carácter práctico del derecho que deriva de las nuevas constituciones, toda vez que la extensión de los conceptos y enunciados es inversamente proporcional a su intención. Así, entre más amplia, la intención de cumplimiento es menor. Por lo tanto, una teoría de la obligación tiene mayor alcance local que la de los derechos fundamentales. Aquello requiere textos constitucionales más acotados o aceptar que la aplicación material de la constitución esté sometida a ser siempre interpretada por los operadores de la justicia, como administradores privilegiados del sistema de garantías.

La existencia de varios órdenes de legitimación jurídica será el origen del sistema de garantías que analizaré en la parte III de este ensayo. Aquí desarrollaré el problema del lenguaje y la estructura de los derechos en el texto constitucional que se enfrentó a tres tesis del sentido común del derecho. (1) Un orden específico de los derechos no da prioridad en la protección, (2) el concepto de ciudadanía es lo suficientemente amplio; y, (3) el lenguaje es común y universal y sirve sólo para la comunicación. Si bien la semántica de Ferrajoli se refiere a la teoría, voy a aplicar este nivel de análisis para el levantamiento del lenguaje estructural en el proceso constituyente de 2007 , como un resultado de la reflexión teórica.

(1) Es común en la política ecuatoriana -posiblemente, también, en otros países de la Región-, por influencia de las/os politólogas/os de los años ochenta que luego en los años no-

\footnotetext{
${ }^{39}$ FERRAJOLI, Luigi, tomo I, Op. Cit., nota 5, p. 4.

${ }^{40}$ Ibidem, pp. 11-14.
} 
venta se transformaron en encuestadores y asesores de imagen de las/os políticas/os, pensar que el orden de las/los candidatas/os en las papeletas de votación condiciona la elección a los que constan de primeras/os. Aquello guardaba relación con la fe de que las reglas e instituciones condicionan la conducta social. Estos mercaderes creyeron que la población sufraga mecánicamente y con una voluntad viciada por tecnicismos que no pueden comprender, posiblemente, fruto de su lectura utilitarista de la obra políticamente conductista de Giovanni Sartori ${ }^{41}$ y de una pléyade de autoras/es extranjeras/os de la escuela norteamericana de ciencias políticas. La cuestión trascendental en la real politics del Ecuador, entonces, sería buscar estar a la cabeza de la lista del partido.

Bajo esta lógica, en la Constitución de 1998 uno de los temas más discutidos, por más baladí que esto parezca, fue el orden de redacción los derechos en el texto constitucional. Aquella superficialidad no era nueva, pues en la Constitución de 1978, la del retorno a la democracia -al menos, formal-, el tema del lenguaje estuvo centrado en el lugar donde deberían estar el capítulo de derechos, ¿en la parte dogmática o en la orgánica de la Constitución? ${ }^{42}$ Por su parte, la correlación de fuerzas políticas del proceso constituyente de 1997 estaba a favor de un sector conservador y tradicional conformado por socialdemócratas, socialcristianos, liberales, populistas, conservadores e independientes. El resultado fue que los derechos de civiles y políticos estuvieron al inicio, luego los económicos, sociales y culturales y finalmente los colectivos. Dentro de los derechos sociales constaban sectores de aplicación: Sección primera: del trabajo, Sección octava: de la educación [...] En este bloque constaban como novedad, los grupos vulnerables. ${ }^{43}$ No obstante, los derechos constaban como una concesión del Estado: El Estado reconocerá y garantizará. Por su parte, integrados a los derechos colectivos estaban los intereses difusos en forma de derechos de los consumidores y al medio ambiente. Los derechos sociales se incluyeron en la Constitución en un lenguaje de política pública, con fines y admoniciones morales y contrarias a un lenguaje laico, como sucedió en lo relativo a la familia que constaba luego de la sección del trabajo, adornado con frases tales como célula fundamental de la sociedad, unión estables y monogámica[...] $]^{44}$ Hubo en la Constitución de 1998, a fin de cuentas, una legitimación constitucional del secuestro total e histórico del sujeto de derecho. Además, en el contexto de una cultura jurídica escritural y formalista, el que la Constitución de 1998 no dijera explícitamente que todos los derechos tienen igual rango y que son directamente aplicables, minó su materialización.

Curiosamente, el discurso del grupo hegemónico para la Constituyente de 1997 fue que el orden de derechos no tenía nada que ver con su garantía. Sin embargo, con referencia al orden de los derechos en la Constitución de 2008, los mismos sectores conservadores se mostraron molestos porque los derechos civiles y políticos -los únicos que consideran justiciables- no estaban al inicio del acápite sobre los derechos. ${ }^{45}$ Afortunadamente, para 2008, fue totalmente lo contrario: no sólo el orden, sino, además, las estructuras conceptuales y el lenguaje del derecho que promocione la realización material de los derechos. Se decidió, entonces, reunir los derechos en siete grupos y el siguiente orden: los derechos del buen vivir

\footnotetext{
${ }^{41}$ SARTORI, Giovanni, ¿Qué es la democracia?, México, Nueva Imagen, 1997; Id., Elementos de Teoría Política, Madrid, Alianza, 1999; Id. Partidos y sistemas de partidos, Madrid, Alianza, 1999.

${ }^{42}$ TRUJILLO VÁSQUEZ, Julio, ¿Actualidad o crisis del constitucionalismo social en el Ecuador?, Quito, Pontificia Universidad Católica del Ecuador, 1977.

${ }^{43}$ Constitución del Ecuador, 1998, art. 16-92.

44 Íbid., art. 37 y 38.

${ }^{45}$ TORRES, Luis Fernando, Presidencialismo Constituyente. Un camino hacia el autoritarismo en el Ecuador, Quito, Cevallos Editora Jurídica, 2009, p. 397.
} 
que son algo más que sinónimo de derechos sociales, pues incluyen la protección del acceso a los recursos vitales; los derechos de las personas y grupos de atención prioritaria (personas con discapacidad, en situación de movilidad humana, entre otros); los derechos de pueblos, nacionalidades, comunas y comunidades indígenas, afroecuatorianos y montubios; los derechos de participación, los derechos de libertad, los derechos de la naturaleza y los derechos de protección. Y en los artículos 10, 11 principios de aplicación de los derechos, y 424-428 (principios de interpretación para la supremacía constitucional) de la Constitución vigente, se intentó fundar el nuevo estatuto de interpretación del derecho en el siglo XXI en reemplazo del caduco título preliminar que todo Código Civil de abolengo napoleónico contiene.

(2) Revolución ciudadana fue el credo del Movimiento Alianza País, organización política que encabezó el proceso constitucional. Se autodenominó parte de una nueva izquierda, la del socialismo del Siglo XXI. Capitalizó esta corriente la crisis política acumulada del Ecuador del primer lustro del presente siglo. Quiebre del sistema financiero y cinco presidentes de la república, de los cuales ninguno terminó el período para el que fue elegido; movilizaciones populares en las calles, levantamientos indígenas y un pedido generalizado de que se vayan todos. Ser ciudadano es un anhelo potente en cualquier parte del mundo, pero más en un país donde el proceso de ampliación de la ciudadanía ha sido más que lento, mezquino, y más que desigual, excluyente. Así, por ejemplo, fue abolida la esclavitud en la Constitución de 1897 , aunque se mantuvo formas precarias como el concertaje, la aparecería y el huasipungo; las mujeres, tempranamente en América Latina, pudieron votar desde la Constitución de 1906 y pudieron comerciar sin permiso de sus cónyuges desde la Constitución de 1967 y las reformas a los códigos, Civil y de Comercio, de 1989. Trabajadores y empleadores, por su parte, fueron igualados en la Constitución de 1929 y a los indígenas, niñas, niños y adolescentes, les tocó su turno en la de 1998.

Ciudadanía universal fue el concepto clave. No obstante, si bien el concepto de ciudadanía funcionó en el mundo occidental como un umbral emancipador, la verdad es que, a medida que se ampliaba, siempre dejaba a alguien fuera. La Revolución Francesa fue un acuerdo entre ciudadanos (no de ciudadanas), respecto de la definición de lo público. Este proceso se realizó por exclusión (es decir, se explica desde quiénes no estaban considerados), no todos/ as concurrieron a este contrato social o, al menos, no lo hicieron en igualdad de condiciones. ${ }^{46}$ Teníamos que buscar un concepto alternativo que, no sólo sea más polivalente, sino además más inclusivo. Ferrajoli en su libro Derechos y garantías. La ley del más débil oponía la ciudadanía a personalidad y capacidad de obrar, alrededor de lo cual gira su definición de derechos fundamentales. ${ }^{47}$ Permitió esto a nuestro autor establecer su idea, tal vez la más criticada, de derechos de la personalidad y derechos de ciudadanía o primarios-sustanciales y secundarios-instrumentales (o de autonomía). ${ }^{48}$ Cobijan a los primeros los derechos humanos y los derechos públicos (primarios) y, a los segundos, los derechos civiles y políticos. Intentaba, en realidad, el maestro determinar lo que es sustancial, por tanto, el límite para el ejercicio del poder, y lo que constituye el marco para las relaciones interpersonales en

\footnotetext{
${ }^{46}$ Véanse: SANTOS, BOAVENTURA DE SOUSA, "Derecho y democracia. La reforma global de la justicia" y su trabajo en: Boaventura De Souza Santos y García Villegas (comps.), El Caleidoscopio de las Justicias en Colombia. Análisis socio-jurídico, Tomo I, Bogotá, Siglo del Hombre Editores, 2001; SANTOS, Boaventura De Sousa, "Los Paisajes de la Justicia en las Sociedades Contemporáneas", en: Boaventura de Sousa Santos y Mauricio García Villegas (eds.), El caleidoscopio de las Justicias en Colombia. Análisis socio-jurídico, Tomo I, Bogotá, Panamerica Formas, 1ra. reimpresión, 2004.

47 FERRAJOLI, Luigi, Derechos y garantías: la ley del más débil, cit., p. 39.

${ }^{48}$ Ibid., p. 40.
} 
su instrumentalidad, en la medida que sería lícito excluir a otros del goce de determinadas prestaciones personales y bienes. Fue un intento de explicar la esencia de las democracias constitucionales y no de establecer rangos o jerarquías entre los derechos, en dos planos de igual importancia: lo sustancial y lo instrumental, con el fin de superar la crisis de la razón formal mediante la razón material en un sistema de garantías que genere un vínculo material entre derecho y democracia: El paradigma de la democracia constitucional no es otro que la sujeción del derecho al derecho generada por la disociación entre vigencia y validez, entre mera legalidad y estricta legalidad, entre forma y sustancia, entre legitimación formal y legitimación sustancial o, si se quiere entre la weberiana racionalidad formal y racionalidad material. $^{49}$

Luego, en la misma obra, el maestro evidencia que luego de la internacionalización de los derechos fundamentales, la mayoría de los Estados atribuyeron los derechos en beneficio de las personas y no de las/os ciudadanas/os, de tal manera que les fueran aplicables con independencia de las fronteras y las nacionalidades. ${ }^{50}$ Advirtió, incluso, la peligrosa tendencia de los Estados ricos a retornar al concepto de ciudadanía por el miedo a las olas migratorias de los años noventa.

Tomamos por todo esto, el concepto de persona como sujeto central de la Constitución de 2008 y nos alejamos del de ciudadanía. Paralelamente, vimos que la categoría derechos fundamentales generaba confusión en la diferencia entre lo sustancial y lo formal propuesta por Ferrajoli, debido a lo establecido en varios textos constitucionales en la región, particularmente la de Colombia de 1991 que tanta influencia ha tenido fuera de sus fronteras, que reservaba la justiciabilidad de los derechos civiles y políticos bajo el encabezado de derechos fundamentales, y condenaba a los derechos económicos, sociales y culturales, y otros a ser considerados meras directrices políticas. Esta idea contradecía lo establecido en la Declaración Universal de Derechos Humanos de 1948, que contiene el proyecto universalista, pero reproduce, al mismo tiempo, lo determinado en los protocolos de Derechos Civiles y de Derechos Económicos, Sociales y Culturales, que deja claro el temor de los estados de estar obligados al bienestar social de sus pueblos, en la máxima los Estados [sociales] están obligados a la garantía de los derechos en la medida de sus recursos disponibles. Utilizamos por ello solamente la categoría derechos. Al constructo jurídico «persona» le dimos un contenido colectivo en todo el texto constitucional y le juntamos el estatuto de derechos bajo el título Derechos del Buen Vivir y las otras clasificaciones mencionadas, siguiendo la propuesta de Boaventura de Sousa Santos ${ }^{51}$ y del grupo de trabajo con Alberto Acosta a la cabeza, presidente de la Asamblea Constituyente: Art. 10.- Las personas, comunidades, pueblos, nacionalidades y colectivos son titulares y gozarán de los derechos garantizados en la Constitución y en los instrumentos internacionales.

Sin embargo, no logramos eliminar la palabra ciudadanía por completo, pues fue duro luchar contra la arraigada tradición que determinados términos tienen en la cultura jurídica y política del Ecuador, además que nos encontrábamos al inicio de la promocionada revolución ciudadana. Pero, al menos, logramos exiliarla del estatuto de derechos, aunque consta como una pieza de museo del nacionalismo fascista en el vestíbulo del auditorio de la

\footnotetext{
49 Ibid., p. 52.

50 Ibid., p. 55.

51 "Las paradojas de nuestro tiempo y la plurinacional”, en Acosta, Alberto, comp., Plurinacionalidad: democracia en la diversidad, Quito, ABYA YALA, 2009.
} 
Constitución de democrática de 2008 en tres disposiciones administrativas del texto constitucional.

(3) Una visión colonial del lenguaje impuso la idea en los países de habla hispana de que el idioma españoles común y universal. La Academia de la Real de la Lengua Española ha sido la defensora del purismo lingüístico. Sin embargo, el idioma español ha evolucionado de manera distinta en cada lugar, en la mayoría de los casos, a espaldas de las reglas y lógicas oficiales de la lengua. Igual debe ocurrir en los otros idiomas. El caso es que esta pretendida pureza de la lengua es una herramienta muy útil para la defensa de la tradición social de las clases dominantes y, por tanto, de su moral particular, y maneras sofisticadas de ser. Quien más se acerque a ella, tiene más posibilidades de ubicarse en la cúspide de la pirámide social. Al mismo tiempo, se entendió que el idioma español servía únicamente para la comunicación interpersonal, posiblemente por la influencia del estructuralismo de Saussure y la preminencia de la supuesta neutralidad de todo saber que heredamos del racionalismo moderno. Sin embargo, a partir del pensamiento de Marx, Weber, Nietzsche, y Freud, la famosa escuela de Frankfort (Horkheimer, Adorno, Benjamin, Marcuse, Fromm, etc.), los postmodernistas franceses de la segunda mitad del siglo XX (Sartre, Foucault, Derridá, Deleuze, Lacan, Bourdieu, etc.), se criticó, tanto a la modernidad y su razón instrumental, como al determinismo de toda estructura social. Revalorizaron así al sujeto en el proceso social.

Un tema común de estas corrientes fue el uso del lenguaje. Contra la teoría y las prácticas sociales, la lengua no sólo es un vehículo de las palabras entre sujetos, sino que tiene características performativas de la conducta humana, condiciona el funcionamiento de las estructuras sociales, y guarda relación con el estado de consciencia o dependencia de los individuos. Aquello influyó fuertemente en el movimiento feminista mundial, especialmente, a partir del famoso suceso conocido como Mayo del 68, que no sólo provocó la dimisión de De Gaulle, sino la emergencia de llamada tercera vía en oposición al comunismo y al capitalismo. Esta idea migró al feminismo en todas partes del mundo, y en América Latina, gracias a los trabajos de Alda Facio ${ }^{52}$ y varias autoras críticas, latinoamericanas ${ }^{53}$ y de la academia estadounidensea partir de variadas perspectivas ${ }^{54}$-en el Ecuador por Judith Salgado, Gina Benavides, Jenny Londoño, Susana Garbay, Gioconda Herrera, entre muchas otras-.

A partir de esto, se habla desde hace una década de la necesidad de incorporar, entre otras cosas, en la redacción de las normas jurídicas en lenguaje de género, que consiste en la fe-

\footnotetext{
${ }^{52}$ FACIO, Alda y LORENA Fries (eds.), Género y Derecho, Santiago de Chile, Ediciones LOM, 1999; FACIO, Alda, "Metodología para el Análisis de Genero y Fenómeno Legal”, en: Género y Derecho, cit.

${ }^{53}$ Véanse: ANZALDÚA, Gloria, "Movimientos de rebeldía y la cultura que traiciona”, en Otras Inapropiables, Creative Commons, California, USA, 2004; FAUR, Leonor, "Género, Masculinidades y Políticas de Conciliación Familia-Trabajo”, Revista Nómadas, núm. 24, abril/20o6, Instituto de Estudios Sociales Contemporáneos, Universidad Central, Bogotá, 2006; Jaramillo, Isabel Cristina, "La Crítica Feminista al Derecho, estudio preliminar", en: Robin West (ed.), Género y Teoría del Derecho, Bogotá, Siglo de Hombres editores, Facultad de Derecho de la Universidad de Los Andes, Ediciones Uniandes, Instituto Pensar, 20oo; LEMAITRE, Julieta, “¿Puede la Corte Constitucional emancipar a las mujeres?”, Universidad de Los Andes, Facultad de Derecho, Observatorio de Justicia Constitucional, 2000.

${ }^{54}$ Por ejemplo: BUTLER, Judith, Deshacer el Género, Editorial Paidós, Madrid, 2004; FRASER, Nancy, Iustitita Interrupta: reflexiones críticas desde la posición "postsocialista”, Universidad de los Andes, Bogotá, 1997; HOOKS, Bell, "Mujeres Negras: dar forma a la teoría feminista”, en: Otras Inapropiables, Creative Commons, California, USA, 2004; WEST, Robin (ed.), Género y Teoría del Derecho, Bogotá, Siglo de Hombres editores, Facultad de Derecho de la Universidad de Los Andes, Ediciones Uniandes, Instituto Pensar, 20oo; WILLS, Maria, “Mujeres y Cuotas Políticas en los Países Andinos”, en: Nadando contra Corriente, Magdalena León ed., UNIFEM y otros, Quito, 2005.
} 
minización de los sustantivos jurídicos y sus adjetivos. Ecuatorianas y ecuatorianos, todas y todos, nosotras y nosotros [...], se han vuelto usos habituales de la arenga política y las normas jurídicas en todos los niveles. Devino inmediatamente en un programa que atravesó el texto constitucional de 2008. Las feministas ecuatorianas no querían ya ser consideradas dentro de los grupos vulnerables como sucedió en la Constitución de 1998. Su intención era dejar de victimizarse desde la misma norma e integrarse estructuralmente al estatuto de derechos, la organización política y la vida social. Por supuesto, su lucha no se agotó en el lenguaje de género, sino que incidió en varios estamentos importantes de la Constitución, tales como la participación política, las acciones afirmativas respecto y las políticas específicas de género. Rompía se pensó esto el carácter asexual con que ha sido construido el derecho tradicional, que es resultado de su condición de supuesta neutralidad.

Recuérdese que el derecho liberal fue erigido como una solución pacificadora de los conflictos culturales y políticos del siglo XVIII, y como un atributo del naciente Estado nación: una sola nación, un solo derecho. Por su parte, el iluminismo racionalista consideró a la igualdad un postulado juridizado: todos somos iguales ante la ley. Es decir, se partió de la idea que, en la realidad, todos somos distintos, pero es en el mundo de las oportunidades que otorga el derecho en donde se puede ejercer libremente la igualdad. Esto plantea dos inconvenientes. Primeramente, sólo dentro del campo jurídico, particularmente en las normas -en el caso de América Latina, sólo las leyes escritas- es posible la realización de la igualdad. $\mathrm{Y}$, en segundo lugar, el establecimiento, normativo y extranormativo, es un abierto atentado al principio de igualdad. Lo primero constituye un discurso de cierre de las posibilidades de garantía, como lo nomina Ferrajoli, sexuada; 55 y, lo segundo impide reformular los derechos fundamentales desde las diferencias sexuales que pertenecen exclusivamente a las mujeres por el solo hecho de serlo. Creo que esto va más allá del ámbito normativo. Afecta la capacidad social de movilizarse por los cambios en intereses de las mujeres y genera resistencia social adversa a toda forma de feminización de la política constitucional. Es decir, la certeza neutra del derecho y su diáfana claridad, sirven en realidad a un orden patriarcal y se reproduce por un ordenamiento jurídico totalmente opaco..$^{56}$ Se reafirma de esta manera el derecho como un discurso de cierre y de mantenimiento del statu quo social, como si fuera un espejo que se apropia de la figura del sujeto impidiéndole verse a sí mismo directamente. En términos teóricos, se explica este fenómeno como la idea originalmente hobbesiana, e históricamente hegemonizada de que la estructura social organizada es la única forma de otorgar equilibrio a una sociedad por naturaleza antagónica. ${ }^{57}$

¿Cómo cabía que en texto constitucional de 2008 se asegurara el derecho de las mujeres a derechos específicos sin afectar el principio de igualdad? Sirvió una vez más la teoría del maestro Ferrajoli a este propósito. Para él, la valoración de las diferencias no rompen el principio de igualdad, todo lo contrario, lo reafirman. ${ }^{58}$ Desde la sustancia normativa, las diferencias operan como libertad negativa de reivindicar estatus alguno; y, desde la garantía-efectividad de los derechos, como libertad positiva de actuación específica en favor las violaciones de derechos de las mujeres. Permitiría esto que la norma se amplíe sin afectar el principio de garantía integrando los valores femeninos como un mínimo y, al mismo tiempo, posibilitando el desarrollo de decisiones específicas en favor de las mujeres. Quiero decir

\footnotetext{
${ }^{55}$ FERRAJOLI, Luigi, Derechos y garantías: la ley del más débil, Op. Cit. nota 24, p. 83.

${ }^{56}$ CÁRCOVA, Carlos María, La opacidad del Derecho, Madrid, Editorial Trotta, 1998.

${ }^{57}$ MOUFFE, Chantal, En torno a lo político, Fondo de Cultura Económica, Buenos Aires, 2007, p. 15.

${ }^{58}$ FERRAJOLI, Luigi, Derechos y garantías: Op. Cit. nota 24, p. 84.
} 
que, de acuerdo a esto, el derecho de las mujeres de decidir sobre su cuerpo formaría parte de sus derechos constitucionales, por lo tanto ya no podría estar penalizado el aborto -como si lo está en nuestros países, total o parcialmente-; y, el Estado estaría obligado a elaborar política de prevención y formación para guiar las decisiones sobre el cuerpo con libertad y responsabilidad, en ejercicio de garantías sexuadas. La teoría de Ferrajoli no alcanzó para tanto, pero otorgó coherencia al establecimiento de las diferencias, especialmente de género -también, las otras formas de tratamiento diferenciado respecto de niñas, niños, adolescentes, jóvenes, personas con discapacidad, con diversa opción sexual, colectivos indígenas, mujeres embarazadas, etc.-. El lenguaje de género, que tanto molestó a los puristas de la lengua, fue una propuesta que estuvo, en menor término, inspirada en su teoría, pero que fue una de las formas que adoptó la estructura constitucional.

A partir de esto, la coherencia estructural del modelo constitucional de 2008 la podemos ver en Principia iuris, puesto que, desde la semántica ocurren tres rupturas (divergencias deónticas). La primera ocurre en el Derecho positivo moderno, en el cual el ordenamiento jurídico encuentra su norma de reconocimiento en la validez, es decir en las normas siguieron un proceso de formación y fueron realizadas por la autoridad competente(diferencia justicia y validez), lo que se diferencia al derecho premoderno que tenía como referencia a la justicia (diferencia entre validez y vigencia).Y luego, sucede cuando se entiende que una ley no es válida sólo por el hecho de ser emanada por un órgano competente, sino porque está, además, preordenada por una norma superior materialmente, la constitución (diferencia entre vigencia y efectividad). Esto representa el paso de un derecho consuetudinario a uno orientado a modificar las prácticas sociales. ${ }^{59}$ Estas divergencias permiten tres enfoques semánticos en el desarrollo de nuestro proceso constituyente: a) filosofía política, b) disciplinas jurídicas positivas; $y, c)$ sociología del derecho. Me parece que estos enfoques jugaron un papel gravitante en la elaboración del texto constitucional de 2008 en Ecuador, en la medida que se lo pensó no sólo como un documento de acuerdo constituyente y comunicación de decisiones, sino como un instrumento de transformación social y cultural frente a una realidad de exclusión y de desigualdad estructurada piramidalmente y asimétricamente transversalizada. Y, paralelamente, la redacción de una constitución dejó de ser un problema exclusivo de juristas, por lo cual se incorporó a otras disciplinas, integrándolas en la dogmática constitucional, y derribando la falaz asepsia histórica e inmaculada del derecho. Toda ciencia del derecho tiene una base empírica, lo cual permite dos enfoques que son dos caras de la mima moneda. Por una parte la dogmática jurídica propia de un enfoque normativista que busca la comprobación de la verdad jurídica a través del estudio del lenguaje jurídico, y la sociología jurídica que tiene un énfasis realista en los hechos y utiliza metodologías empíricas sociológicas. ${ }^{60}$

El fin del uso del lenguaje constitucional analizado en esta parte era influir en los patrones culturales en todos los niveles, pero, particularmente, en los estamentos estatales, de tal manera que la protección de personas y colectivos se maximice. No obstante, la cultura constitucional es aún muy pobre luego de casi un lustro de vigencia de la Constitución de 2008. En un estudio empírico-cualitativo que dirigí desde la Corte Constitucional a inicios de este año, los hallazgos son sorprendentes: la Constitución en un porcentaje del $87 \%$ es poco conocida (de ese porcentaje, 15, $1 \%$ nada conocida); $29 \%$ considera que es poco importante (un $4 \%$ piensa que es nada importante); $73 \%$ de las personas encuestadas cree que

\footnotetext{
${ }^{59}$ FERRAJOLI, Luigi, Principia iuris. tomo I, Op. Cit., nota 5, pp. 15-17.

${ }^{60}$ Ibid, pp. 7-11.
} 
la Constitución se cumple poco; y, el 72, 6\% piensa que una persona debe estar detenida indefinidamente por el solo hecho de ser sospechosa de haber cometido una infracción. ${ }^{61}$

Posiblemente, es necesario más tiempo y más políticas estructurales de amplio espectro que integren el lenguaje de derechos de la Constitución a la realidad cotidiana y acompañen los procesos históricos de garantía de los derechos: voluntad política permanente por la transformación y ciudadanas/os activas/os y protagónicas/os.

\section{LA PRAGMÁTICA: LAS GARANTÍAS Y LA DEMOCRACIA SUSTANCIAL}

De acuerdo al plan metodológico de Principia iuris, la pragmática que se refiere al campo de las opciones que intervienen en la construcción de la teoría y en la explicación de los principios que sustenta. ${ }^{62}$ También, se relaciona con el proceso de elección de opciones para la construcción del lenguaje jurídico, que se rige por la teoría en su necesidad de aplicaciones explicativas, y por el sentido común con su afán práctico de regulación. Respecto de lo que nos planteamos en este ensayo, la idea es establecer la existencia de varios órdenes de legitimación jurídica en el origen del sistema de garantías. Si el texto constitucional, a pesar de la aparente homogeneidad política de las/os integrantes de la Asamblea Constituyente, es de por sí heterogéneo, diverso; también, lo fue el mismo proceso constituyente. Múltiples intereses rondaron las mesas de discusión, diferentes perspectivas y enfoques de todos los sectores sociales jugaron un rol de prefiguración de la constitución. ¿Qué le daría coherencia y unidad ideológica?, ¿cómo conciliar el desarrollo con el buen vivir?, ¿qué permitiría combinar los mecanismos de representación y la democracia participativa?, ¿cómo equilibrar la emergencia de la planificación económica sin desconocer totalmente el mercado? Por supuesto, existían muchas opciones y actores políticos de todo tipo. Hubo, incluso, propuestas sumamente curiosas, como la que proponía que la constitución cree una sociedad celestial controlada por complicadas reglas sociales de natalidad y educación con el fin de relacionarse con los extraterrestres.

Ante esta diversidad, la opción mítico-estructural fue la democracia sustancial como contrapartida del Estado constitucional. Pero, ¿qué representa este nuevo adjetivo al sustantivo tan manoseado de democracia?, y ¿qué verbo sería adecuado para darle materialidad? Escogimos sustancial y el instrumental garantizar con este fin.

A esta altura, creo que podemos considerar a la constitución y al mismo proceso constituyente como fenómenos culturales, condicionados históricamente por una suerte de continuidad histórica que se encuentra abierta todo el tiempo a su mejoramiento. ${ }^{63}$ Nuestro caso ecuatoriano en la Asamblea de 2007 fue una evidencia clara de esta afirmación. De acuerdo a esto, el Estado constitucional no sólo es fruto de una decisión política coyuntural, sino el resultado de un proceso de perfeccionamiento histórico: un producto histórico. Este postulado se aleja de lo establecido por Ferrajoli, según el cual la constitución sería un producto en gran medida artificial y conformado por normas positivas convencionales. Sin embargo, me parece que ambas perspectivas, la cultural y la normativa, son plenamente compatibles, sólo que se refiere a dos distintos niveles de análisis de la realidad constitucional. Lo que se

\footnotetext{
${ }^{61}$ DONOSO, Juan Carlos, Base de datos cualitativa sobre cultura constitucional, Ecuador, Corte Constitucional, Proyecto SIMEC, diciembre 2012.

${ }^{62}$ FERRAJOLI, Luigi, Principia iuris.tomo I, Op. Cit., nota 5, p. 4.

${ }^{63}$ HÄBERLE, Peter, El estado constitucional, IIJ-Universidad Nacional Autónoma de México, 2003; Íd., Teoría de la constitución como ciencia de la cultura, Madrid, Tecnos, 2000.
} 
alega desde una mirada normativa, es que los textos constitucionales son un nivel más del ordenamiento que desarrolla el deber ser (y el no ser), en la medida que impone reglas y límites al poder, mediante las garantías; por lo cual el Derecho es una precondición material para la existencia de la democracia, entendida ésta como un límite sustancial. Mientras, que esto está conectado con el carácter inmanente y evolutivo de la dignidad humana culturalmente decidida en forma de Estado constitucional.

Me parece que este nivel histórico-cultural es importante para entender la apropiación de los conceptos ferrajolianos de democracia sustancial y garantías, en la necesidad de que el texto constitucional permita reafirmar las conquistas sociales de los grupos menos favorecidos de la sociedad ecuatoriana, y que la acción política permita, igualmente perpetuarlos, al mismo tiempo que desarrolle otras. Por esta razón, en los trabajos de Ramiro Ávila y Julio César Trujillo -en los míos sobre el sistema de justicia-, el Estado constitucional se representa como un antídoto al Estado tradicional o liberal, ${ }^{64}$ o como un nuevo Estado que resultó de una metamorfosis social. ${ }^{65}$ En mi visión, algo integradora pero también distinta, la Constitución es un instrumento de transformación política que tiene como fin generar, no sólo legitimidad de origen y de ejercicio al sistema político, sino también material. Esta forma de legitimidad se refiere a la necesidad de reivindicar el constitucionalismo de los pueblos excluidos por la violencia colonizadora, el patriarcalismo, la inequidad y capitalismo depredador. ${ }^{66}$

Nuestra opción fue el Estado constitucional, la sustancia; las garantías, el instrumento para darle estructuralidad al texto constitucional y potencial emancipador frente a las acusaciones livianas de sectores conservadores que ven en el proceso constituyente y la Constitución de 2008 un proyecto autoritario y de socialismo mercantilista.$^{67}$

El ideal-discurso de las garantías surgió de la obra tan comentada en este ensayo, Derecho y garantías. La ley del más débil, pero también desde el lado del garantismo penal de Derecho y Razón. Teoría del garantismo penal. Nuestro sistema punitivo en su dogmática penal no ha tenido cambios importantes desde la importación del Código Rocco de la década de los cuarenta, el cual a su vez modernizó -o perfección la maquinaria de punición autoritaria- el Código Penal napoleónico. El aparato punitivo ecuatoriano es casi el mismo del termidor francés que significó, si asumimos la metárfora de Pisarello, el retroceso antidemocrático de Europa a finales del siglo XIX.$^{68}$ Debido a esto, las garantías estuvieron pensadas con un énfasis en el garantismo penal.

Al mismo tiempo, el sistema de garantías no era nuevo para 2007, puesto que ya existía desde las reformas constitucionales de 1996 y la Constitución de 1998. Durante el final de la década de los ochenta y toda la década de los noventa, en el Ecuador y los demás países de la

\footnotetext{
${ }^{64}$ ÁVILA SANTAMARÍA, Ramiro, "Estado Constitucional de Derechos y Justicia”, en: Ramiro Ávila (ed.), La Constitución de 2008 en el Contexto Andino. Análisis desde la doctrina y el derecho comparado, Quito, Ministerio de Justicia, 2008.

${ }^{65}$ TRUJILlO VÁZQUEZ, Julio, “El Estado en la Constitución”, en: Viciano, Roberto (ed.), Estudios sobre la constitución ecuatoriana de 1998, Valencia, CEPS, Universidad Andina Simón Bolívar, Sede Ecuador, 2005.

${ }^{66}$ ÁVILA LINZÁN, y VALLE, Alex, “¿Derecho de la miseria o miseria del Derecho?”, en Enzo Bello y otros, Dereito y Marxismo. Tendencias atuais, Universidade de Caxías, Brasil, 2012; ÁVILA LINZÁN, y VALLE, Alex, "Derecho de la miseria o miseria del derecho", en: Luis Fernando Ávila Linzán, Emancipación y Transformación Constitucional, Corte Constitucional, 2011.

${ }^{67}$ TORRES, Luis Fernando, “¿Cómo cambió el Ecuador entre el 2007 y el 2009?, en: Luis Fernando Torres (ed.), Debate Constitucional. Monografías, Quito, Fundación Hans Seidel, 2010, pp. 18-26.

${ }^{68}$ PISARELLO, Gerardo, Un largo Termidor: historia y crítica del constitucionalismo antidemocrático, Cit.
} 
región ocurrieron varios casos graves de violación de derechos humanos, relacionados con ejecuciones extrajudiciales, desapariciones forzosas, torturas, y privaciones ilegales de libertad en el contexto de la lucha contra la insurgencia armada, y los sindicatos y movimientos sociales en resistencia a las políticas neoliberales. Muchos casos fueron conocidos por la Corte Interamericana de Derechos Humanos. Su diagnóstico casuístico y sistemático apuntaba a la ausencia total de mecanismos concretos de protección nacional de los derechos humanos. Fue así que a partir de los modelos mexicano, colombiano y español (acción de amparo o tutela), la mayoría de países de la región implementó jurisdicciones especializadas con el fin mencionado. No obstante, las reformas aún fueron muy tímidas. Estuvieron contaminadas de la lógica de los tradicionales derechos, civil y administrativo. Por tal razón, estuvieron concebidos como remedios procesales (recursos y no acciones) para suspender un acto de autoridad pública que viole o pueda violar un derecho constitucional, y sólo cuando se haya agotado toda vía ordinaria (judicial y administrativa). Vale decir, el amparo constitucional fue un recurso procesal de tipo cautelar y residual; mientras, que la tradición individual-civilista de los derechos humanos, profundamente enraizada en la cultura judicial y jurídica de las/os operadoras/es de la justicia y la población en general, sólo consideró que los derechos civiles y políticos eran verdaderos derechos, por tanto, justiciables y aplicables directamente. Los demás derechos, así nominados en nuestras constituciones, sólo fueron considerados como normas programáticas o meras directrices políticas para la aplicación de los derechos individuales. ${ }^{69}$ Por su parte, los libros ya comentados, editados por Carbonell, Neoconstitucionalismo(s) (1998) y Teoría del Neoconstitucionalismo (2003), contenían como uno de los problemas centrales del derecho y las garantías en América Latina, el de la no aplicación de los derechos sociales.

De esta manera, la principal agenda del sistema de garantía fue la integralidad de los derechos y de los mecanismos de garantía. La idea era que ningún acto, público o privado, quedaran fuera de control del derecho.

Para el maestro Ferrajoli, toda vez que el concepto dominante sobre democracia es procedimental, considera que toda vez que este es un proceso público de formación de la decisión, que se fundamenta en el poder del pueblo, propone establecer algún vínculo material o de contenido sobre la base de la integración de las dimensiones formal y material, las formas jurídicas (civil y política), y los contenidos normativos (liberales y sociales), en todos los niveles (estatales, supraestatales e infraestatales). El maestro antepone así al concepto procedimental el de democracia sustancial. No se trata de una teoría formal del derecho, sino normativa que surge de una interpretación axiomática que se hace necesario por cuatro razones. La primera es la escaza capacidad explicativa de la democracia procedural; la segunda, es que aquella no es consistente consigo misma; la tercera, porque una concepción sólo formal centra su atención exclusiva en los derechos primarios de libertad; y, cuarta, porque las teorías formalistas de la democracia parten de una aporía respecto de la representación y su relación con el pueblo. Esta relación es posible, no sólo por el mecanismo de participación

\footnotetext{
${ }^{69}$ ABRAMÓVICH, Víctor, Acceso a la justicia como garantía de los derechos económicos, sociales y culturales. Estudio fijado por la Corte Interamericana de Derechos Humanos, Costa Rica, Corte Interamericana de Derechos Humanos, 2007; García Villegas, Mauricio, “Derechos sociales y necesidades políticas. La eficacia jurídica de los derechos sociales en el constitucionalismo colombiano”, en: Boventura De Sousa Santos, El caleidoscopio de las justicias en Colombia. Análisis socio-jurídico, cit.; UPRIMNY, Rodrigo, "Las transformaciones de la administración de justicia en Colombia”, en: El caleidoscopio de las justicias en Colombia. Análisis socio-jurídico, cit.
} 
de las mayorías, sino por el ejercicio de los contrapoderes, materializados en los derechos fundamentales. ${ }^{70}$

Como un resultado histórico-evolutivo, un ordenamiento premoderno de tipo legislativo que se caracterizaba por el principio de legalidad, se convirtió en un moderno ordenamiento del constitucionalismo jurídico regido por el principio de estricta legalidad, es decir, vinculado al contenido de los principios constitucionales. Este proceso de transformación se debió a las grandes revoluciones y guerras mundiales, particularmente, la preeminencia del positivismo jurídico, y el impacto de los cambios culturales y las revoluciones teóricas. Un evento importante fue, entonces, la positivización de las constituciones mediante el principio de rigidez constitucional y la implementación de mecanismos de garantía de la supremacía y justicia constitucional -interacción entre cambios culturales e institucionales. ${ }^{71}$ Por supuesto, el sustancialismo jurídico no es nuevo, pues estuvo presente en el derecho jurisprudencial moderno, desconocido por el primer positivismo, pero es distinto al del Estado constitucional en la medida en que éste no es parte de la arbitrariedad subjetiva del juzgador, sino que constituye un límite-vínculo impuesto al legislador en normas pactadas y positivadas. Nos recuerda el maestro, que de la tipología de regímenes nombrada se produce modelos de racionalidad: (1) el propio del Estado absolutista -Ancient Régime- (instrumental), (2) el Estado legal (formal); y, (3) Estado Constitucional (sustancial):

El ius-naturalismo, aun dentro de todas sus variantes, fue la filosofía jurídica dominante de la época premoderna, mientras faltó un sistema formalizado de fuentes basado en el monopolio estatal de la producción jurídica. El ius-positivismo lo fue después de las codificaciones y el nacimiento del Estado moderno. El ius-constitucionalismo lo es hoy, o en todo caso se está convirtiendo en ella, tras la introducción de las garantías jurisdiccionales en apoyo de la rigidez de las constituciones. $^{72}$

Tomamos, en todo caso, en nuestro proceso constituyente de 2007 la democracia sustancial y las garantías desde el pensamiento de Ferrajoli, pero con nuestros propios significados. La democracia constitucional se convirtió en un modelo omnicomprensivo de todos los intereses sociales, y las garantías en instrumentos para darle operatividad a los derechos constitucionales. Ambos conceptos, incluso, fueron integrados al texto constitucional en tanto instrumento de transformación social. Consecuentemente, la democracia constitucional se convirtió en un eje vertebrador del texto constitucional y de equilibrio político, como límite, pero también, como frontera y espacio de opciones y deliberación política, permitiendo la convivencia de la democracia participativa, con la representativa; la planificación con el mercado[...] Mientras que las garantías, se concibieron como el engranaje de la máquina constitucional, que debería ser accionado por cualquier ciudadana/o, ante la posible violación de derechos y para exigir la materialización de los derechos. Este Estado estaría obligado negativamente, pero también positivamente, por lo tanto sería responsable no sólo de la omisión de violación de derechos, sino de la implementación de decisiones particulares para el desarrollo y materialización de los derechos. Pasó así el Estado ecuatoriano de ser un aparato mínimo a uno máximo, de uno que tiene que priorizar sus políticas a uno que debe maximizarlas; y, de uno que tiene que omitir a uno que tiene que actuar. El Estado constitu-

\footnotetext{
${ }^{70}$ FERRAJOLI, Luigi, Principia iuris. tomo II, Op. Cit., p. 1-12.

${ }^{71}$ Ibid. p. 20.

${ }^{72}$ Ibid. p. 41 .
}

CIENCIA JuRÍDICA. Departamento de Derecho. División de Derecho, Política y Gobierno, Universidad de Guanajuato - Año 5, No. 10, 2016 
cional es abiertamente interventor, pero no totalitario ni autoritario, pues estos fenómenos no son resultado directo de normas jurídicas, sino de la existencia de estructuras de exclusión política o de la falta de mecanismos de intermediación social. No obstante, esta naturaleza garantista del Estado ha sido percibida, también, como estatista, socialista mercantilista y otros apelativos sin ningún sustento teórico, donde se confunde intervención -obligación positiva- como sinónimo de autoritarismo-. ${ }^{73}$

Desde la idea de la sustancialidad y el garantismo constitucional, las garantías en la nueva Constitución pasaron a ser una jurisdicción de conocimiento y reparación, y de creación de derechos desde el sistema de justicia. Se separó así en el texto constitucional la garantía (potencial de actuación) de lo sustantivo (límite de no injerencia y desarrollo). ${ }^{74}$ Las/os juezas/ es dejaron de ser la boca que dice la ley a ser creadoras/es del Derecho y, por tanto, quienes otorgan legitimidad a la democracia, con funciones no sólo jurídicas, sino, también, políticas y sociales. ${ }^{75}$

Frente a esto, pocos estudios sobre la legitimidad social y el impacto social de las garantías constitucionales, particularmente de la acción de amparo constitucional, se han realizado en Ecuador, pero los que han sido desarrollados dan algunas pistas que pueden hacer sospechar que las garantías no logran calar aún muy hondo en la sociedad ecuatoriana y su impacto es mínimo, la cual percibe, a su vez, su aplicación como politizada y abusiva. Así, un estudio realizado por Agustín Grijalva y Alex Valle pone en evidencia que la práctica jurídica del Tribunal Constitucional logró la exclusión e inexigibilidad de los derechos económicos sociales y culturales. Pues resulta claro que la acción de amparo concentró su protección en temas puramente administrativos (36.26 \%), y la protección a derechos sociales pasó a un segundo plano (22.2 \%). Resulta sorprendente que apenas el o,44 \% del total de casos analizados se refirió a la protección del derecho a la seguridad social, y a $2 \%$ del total de casos sobre derechos sociales; mientras, que sólo el 1,32 \% correspondiente al derecho a la educación del total de casos y de $6 \%$ con relación al total de derechos sociales. ${ }^{76}$ Más sorprendente resulta si lo comparamos con el aún insuficiente énfasis en protección de derechos sociales por parte de la Corte Constitucional para el período de transición. ${ }^{77}$

A pesar de todo esto, igualmente se intuye que la acción de amparo ha contribuido al fortalecimiento de la justicia y el Estado constitucional, entendido éste como un régimen de garantía constitucional de los derechos constitucionales, pero que, no obstante, no ha sido suficiente para alcanzar legitimidad social e impacto jurídico profundo en la realidad ecuatoriana: ¿Hasta cuándo el abuso de las acciones de garantía constitucional? Hasta que se frenen los abusos a los derechos humanos de las personas. Si alguien puede abusar de una garantía, es el poder público por una mala interpretación y aplicación de la garantía. Si al-

\footnotetext{
73 TORRES, Luis Fernando, Presidencialismo Constituyente. Un camino hacia el autoritarismo en el Ecuador, Quito, Cevallos Editora Jurídica, 2009.

74 GRIJALVA, Agustín, “Acción Extraordinaria de Protección”, en Claudia Escobar, Teoría Práctica de la Justicia Constitucional, Quito, Ministerio de Justicia y Derechos Humanos, 2010.

75 SOUSA, Santos Boaventura, De la Mano de Alicia. Lo social y lo político en la postmodernidad, Bogotá, Ediciones Uniandes, 2001.

${ }^{76}$ GRIJALVA, Agustín y VALLE, Alex, Uso y funcionamiento de la justicia constitucional, Quito, Ministerio de Justicia y Derechos Humanos, 2010, p. 8.

77 Ibíd., pp. 10-14.
} 
guien tiene el derecho de abusar de las garantías son las víctimas de violaciones a los derechos humanos. $^{78}$

La situación actual de aplicación de las garantías no ha variado sustancialmente. No obstante, las opciones políticas que plantean el Estado constitucional y el sistema de garantía desde la Constitución de 2008 requieren una ciudadanía activa y preocupada por el ejercicio y materialidad de los derechos, no sólo porque se siente afectada/o, sino porque, además, está integrado a un estilo de vida garantista, donde el derecho no termina donde comienza el del otro, sino que guarda una solución de continuidad con el otro y con las luchas sociales de nuestros pueblos. Sin embargo, existen tantas políticas en nombre del Estado constitucional, la democracia sustancial y del garantismo, que hoy es imposible analizar nuestra realidad constitucional sin hacer una referencia a sus elementos y mecanismos, a su naturaleza y utilidad, a sus defensoras/es y sus detractoras/es. Estos conceptos fueron el marco pragmático que permitió la coexistencia de varios discursos emancipadores y la reformulación de los clásicos, en el proceso constituyente.

\section{LA SINTÁCTICA: EL PROYECTO GARANTISTA DE TRANSFORMACIÓN CONSTITUCIONAL}

Finalmente, en la propuesta metodológica de Principia iuris, tenemos la sintáctica que se encarga de explicar los procedimientos de formación y control que formula la teoría axiomática. ${ }^{79}$ La sintáctica se refiere al método de las ciencias jurídicas, que tiene dos niveles, el del leguaje y el del discurso. El uno viene de la observación empírica y directa de la realidad (lenguajes observacionales), y el otro de la teorización (lenguajes teóricos), en la que la semántica permite establecer proposiciones interpretativas sobre un fenómeno o determinados hechos. Estos fenómenos corresponden respectivamente a la dogmática jurídica y a la teoría del derecho. Para efectos del presente ensayo, este elemento metodológico permite abrir al infinito el espacio de elección política (pragmática) e instrumentalizar la teoría hecha lenguaje (semántica). En este sentido, el texto constitucional deviene en un proyecto de transformación constitucional, más concretamente desde la constitución. Se vuelve un instrumento de transformación política. Esto permitirá que el texto constitucional se amplíe y adquiera vida social renovada, por la lucha social que instrumente las garantías entre sus estrategias de incidencia política; y, que los cambios ocurran pacífica y permanentemente (la sintáctica). Va esto más allá este anhelo del derecho vivo propuesto por Ehrlich a principios del siglo XX. El puente estructural que permitió esta naturaleza instrumental de la Constitución fue en el proceso constituyente la categoría soberanía.

Igual como ocurrió durante la Revolución Francesa, las palabras revolucionarias fueron soberanía y soberano. Respecto del significado de soberanía, se entendió que era un atributo de la nación o del pueblo como capacidad de decidir y administrar el poder, como una contrapartida de la ciudadanía, como atributo de actuación jurídica y autónoma. La ficción que le permitió funcionar a este sistema político fue la representación política para dar forma a los intereses del pueblo o nación soberanos; mientras que el ordenamiento jurídico y de administración de justicia sería el canal para el ejercicio de la ciudadanía. A pesar de la dicotomía entre soberanía nacional y popular, hoy podemos decir que existe una tendencia

\footnotetext{
${ }^{78}$ ÁVILA SANTAMARÍA, Ramiro, “El amparo constitucional: entre el diseño liberal y la práctica formal”, en: Un cambio ineludible: la Corte Constitucional, Tribunal Constitucional, Quito, 2008.

79 FERRAJOLI, Luigi, Principia iuris, tomo I, Op. Cit., nota 5, p. 4.
} 
paulatina y sostenida hacia el afianzamiento de ideal popular de la soberanía, incluso hasta llegar a pensar en una ciudadanía universal. ${ }^{80}$

El tránsito de ciudadanía popular a universal parte de la idea de democracia sustancial ya desarrollada. Para Ferrajoli, la democracia sustancia surge del ideal original de soberanía popular, la cual tiene dos formas de ser entendida. Por una parte, como garantía negativa que limita la apropiación de aquella para usarla contra los demás (reside en o pertenece al pueblo) (Rousseau), y en sentido positivo como una posibilidad de agregación de sustancia a los mecanismos formales y los derechos fundamentales (Constant). Esta dimensión sustancial es la esencia de un Estado constitucional. Por tanto, existe entre democracia y Derecho un nexo racional (teórico, metateórico y práctico), de tal manera que los derechos primarios (los de actuación) son precondición de los de autonomía secundarios (los de omisión): los unos conforman parte de una dimensión sustancial y los otros de una dimensión instrumental. Tiene así la democracia una naturaleza cuatridimensional (política, civil, liberal y social). Por lo cual, los derechos civiles establecen prohibiciones que imponen límites a la posible lesión y su incumplimiento genera antinomias; mientras que los derechos sociales, determinan vínculos para el ejercicio de prestaciones, y su incumplimiento produce lagunas (normas téticas y hipotéticas). De esta manera, los tipos de democracia presuponen la democracia política, pero no lo contrario, al mismo tiempo que todos los tipos de democracia son todas necesarias para la democracia constitucional. Es posible, a partir de esto, establecer niveles y grados de desarrollo de la democracia de acuerdo a la cantidad y calidad de los derechos incorporados a las constituciones, y las funciones del gobierno (nomoestática) y de garantía (nomodinámica). ${ }^{81}$

A partir de esto, las democracias se legitiman formalmente mediante la identificación de los procedimientos para la construcción de la representación, y sustancialmente en los límites y vínculos impuestos a los contenidos de la producción jurídica (positiva o negativa). Es, al mismo tiempo, la legitimación sustancial negativa la permisión de la funciones de gobierno y positiva el ejercicio de las garantías. El uno es propio de un Estado legal (o Estado de Derecho débil) y el otro de un Estado constitucional (o Estado de Derecho fuerte) ${ }^{82}$

De este proceso de sustancilización de la democracia, una constitución democrática es un conjunto de principios formales y sustanciales, dirigidos a los poderes del Estado y a todas/ os las/os personas, como límite y vínculo, ${ }^{83}$ puesto que las constituciones son pactos políticos, en principio, entre desiguales. No necesariamente, como se ha pensado, entre iguales y con cierta homogeneidad. Se contrapone esta idea a la tesis organicista del iuspublicismo alemán que considera al pueblo como unidad política, con lo cual una constitución es la expresión de su unidad política. Desde una perspectiva garantista, al contrario, es un pacto de convivencia que se vuelve necesario en la medida que las diferencias sociales y políticas son mayores. En este sentido, las constituciones no se legitiman en la aprobación popular, sino en la medida que permita, a través de las garantías, oponerse a las mayorías. ${ }^{84}$

A partir de estas ideas, la categoría soberanía en el proceso constituyente de 2007 sirvió para la extensión del espacio de decisión política y atenuación de la representación política;

\footnotetext{
${ }^{80}$ FERRAJOLI, Luigi, “Más Allá de la Soberanía y Ciudadanía: un constitucionalismo global”, en: Miguel Carbonel y Rodolfo Vásquez (coords.), Estado Constitucional y Globalización, México, Porrúa UNAM, 2001.

${ }^{81}$ FERRAJOLI, Luigi, Principia iuris. Teoría del Derecho y de la Democracia, tomo I, Op. Cit., p. 27.

${ }^{82}$ Ibíd., p. 31.

${ }^{83}$ FERRAJOLI, Luigi, Principia iuris. Teoría del Derecho y de la Democracia, tomo II, Op. Cit., nota 2, pp. 42-47.

${ }^{84}$ Ibíd., p. 56.
} 
la democracia participativa, las consultas populares, las rendiciones de cuentas y la revocatoria del mandato que son ejemplos de esto. Y, para otorgar vínculo social a las garantías constitucionales (jurisdiccionales, de la política pública y normativa), tenemos, entre otras, la legitimación procesal de acción popular, la obligación de realizar audiencias en los procesos constitucionales, y los peritajes constitucionales.

Pero el proceso constitucional nuestro le dio un significado adicional a la clásica categoría soberanía. De una parte, nuestro proceso asumió el significado histórico del constitucionalismo nacional: la soberanía como sinónimo de control sobre el territorio, luego de la experiencia de desmembramiento permanente en favor de nuestros países vecinos. Por la otra, se la concibió como un espacio de maximización del poder popular en todos los niveles, y como un instrumento para recuperar el control sobre los recursos naturales. Razón por la cual en el texto constitucional se habla de soberanía alimentaria, soberanía energética, soberanía económica, y soberanía sobre la diversidad. Evidentemente, esta extensión de esta clásica categoría no está exenta de polémica, y hay quienes ven en este fenómeno un debilitamiento del poder soberano, pues la entienden como la capacidad de imponer su voluntad de manera legítima. ${ }^{85}$ Veamos, no obstante, el tratamiento que el texto constitucional le da a la soberanía popular como una sustancia estructural y holística:

Art. 1.- [...] La soberanía radica en el pueblo, cuya voluntad es el fundamento de la autoridad, y se ejerce a través de los órganos del poder público y de las formas de participación directa previstas en la Constitución.

Los recursos naturales no renovables del territorio del Estado pertenecen a su patrimonio inalienable, irrenunciable e imprescriptible.

Una Constitución como ésta no puede ser sino igualmente soberana y toda actuación en su nombre deberá también tener la misma naturaleza. Exige esta renovada naturaleza constitucional un giro epistémico en el Derecho, que recupere el valor político del Derecho y que visibilice lo social en su desarrollo. Debe surgir un derecho desde el sur, profundamente crítico con el poder y el proceso de alienación política de América Latina, que ha permitido la apropiación del derecho por las clases dominantes, y el inmovilismo social. ${ }^{86}$ No obstante, luego de transcurridos cinco años de la puesta en vigencia de la Constitución de 2008, lentamente, el régimen político se ha ido alejando del lenguaje constitucional, del carácter sustancial y participativo, y del uso instrumental de su contenido para la transformación social. Posiblemente, la beligerancia de la transición política que significó este proceso histórico, luego se fue apagando, o comenzaron a emerger las profundas estructuras reales que atraviesan nuestra sociedad, haciéndose cada vez más visibles. $\mathrm{O}$, posiblemente, tal como lo previera Lasalle, una Constitución no es más que el resultado de la correlación de fuerzas políticas realmente existentes en una sociedad. ${ }^{87}$ En todo caso, existen algunas rupturas históricas e importantes a partir de la política constitucional desde la Constitución de 2008, pero, al mismo tiempo, también algunos retrocesos. Un ejemplo de esto es la consulta popular organizada en 2010 para la intervención del sistema de justicia. Sin perjuicio de los

\footnotetext{
85 TORRES, Luis Fernando, Presidencialismo Constituyente. Un camino hacia el autoritarismo en el Ecuador, Op. Cit. nota 45, pp. 396-397.

${ }^{86}$ ÁVILA LINZÁN, Luis Fernando y Valle, Alex, “¿Derecho de la miseria o miseria del Derecho?”, en Enzo Bello y otros, Dereito y Marxismo. Tendencias atuais, Universidade de Caxías, Brasil, 2012.

${ }^{87}$ LASALLE, Ferdinand, ¿Qué es una Constitución?, Barcelona, Editorial Ariel, 1989.
} 
problemas estrictamente jurídicos, especialmente, si una reforma de esta magnitud afecta la estructura general del Estado y, por tanto, está por fuera de lo que se puede modificar, por lo cual debió ser objeto de un proceso constituyente; esta intervención boicoteó la intención original de que la transformación constitucional fuera liderada por el sistema de justicia, por operadoras/es y servidoras/es, otorgando legitimidad material a nuestra Constitución. ${ }^{88}$ Un efecto colateral, pero grave de esta reforma constitucional ha sido el retorno del eficientismo judicial que desconoce el carácter estructural y políticamente comprometido que deben tener las políticas de justicia desde el sistema de justicia, tanto ordinario como constitucional, con el fin de asegurar un acceso sustancial a la justicia e independencia judicial interna, ideológicamente dirigida a la emancipación social. ${ }^{89}$

\section{CONCLUSIONES. EL GARANTISMO COMO HORIZONTE}

Las constituciones democráticas son las leyes del más débil,90 puede ser una frase que resume el pensamiento de Luigi Ferrajoli y la obra que aquí he comentado. A partir de esta afirmación, puede entenderse claramente por qué los Derechos Humanos, como teoría, política o sociedad, no es una teoría neutra. En Ecuador, el común de la gente cree que está para defender a violadores, homosexuales, delincuentes, descuidando su atención respecto de las víctimas y el estándar de la sociedad. Que no sea una teoría neutra significa, justamente, que toma una opción política. Y la opción política de los derechos humanos es por las/os más débiles. Por supuesto, por quienes son estructuralmente los más débiles, no aquel que en la coyuntura de la comisión de un robo a mano armada le toca someterse a la violencia de un ladrón de carteras. Quienes no han tenido oportunidades históricas de decidir, quienes no tienen capacidades ni oportunidades en igualdad de condición con los más ricos, quienes se defienden de haber sido juzgados previamente por los medios de comunicación y por la gente de bien, el aparato punitivo-represor del Estado, y jueces burocratizados e indolentes. Todos ellos son la opción de los derechos humanos hoy. Y si el derecho constitucional es sólo una cara de la misma moneda, también le corresponde tomar la misma opción. No obstante, es la cara más visible ante la realidad de exclusión y pobreza, el abuso de los poderosos, y el secuestro de la esperanza en una América Latina colonizada por intereses de las transnacionales, la satrapía de los feudos locales, y el imperialismo de los países centrales. Las garantías pueden y deben convertirse en herramientas jurídicas junto a una jurisprudencia insurgente y con legitimidad material que consoliden las conquistas sociales e históricas. ${ }^{91}$

Se busca una revolución histórica en el constitucionalismo latinoamericano que depure el carácter de instrumento de dominación que tienen históricamente el Estado y el derecho, poniéndolo al alcance de las personas y colectivos como una herramienta de los cambios

\footnotetext{
${ }^{88}$ ÁVILA LINZÁN, Luis Fernando, Emancipación y Transformación Constitucional, Corte Constitucional, 2011.

${ }^{89}$ Véanse: ÁVILA LINZÁN, Luis Fernando, "Política de reforma constitucional por vía de consulta popular en Ecuador: ¿ingenuidad, sinceramiento o estrategia?”, en revista Rebelión (virtual): www.rebelion.ogr, 2011; Íd., "La Constitucionalización de la Administración de Justicia”, en Ramiro Ávila (ed.), La Constitución del 2008 en el contexto andino. Análisis desde la doctrina y el derecho comparado, Ministerio de Justicia y Derechos Humanos, Quito, 2008; Íd., "El acceso a la justicia y la emancipación social de las personas excluidas", en Ramiro Ávila, (ed.), Neoconstitucionalismo y sociedad, Ministerio de Justicia y Derechos Humanos, Quito.

$9^{\circ}$ FERRAJOLI, Luigi, Principia iuris. Teoría del Derecho y de la Democracia, tomo II, Op. Cit. nota 2, p. 57.

${ }^{91}$ TIGAR, Michael y LEVY, Madelaine, 1973, “La Jurisprudencia Insurgente”, en José María Martinelli (comp.), Lecturas sobre Derecho y Derecho Económico, Universidad Autónoma Metropolitana- Iztapala, México. 
y resistencia frente a las clases dominantes. No obstante, no debemos olvidar que nos encontramos ante un constitucionalismo de transición, por lo cual las contradicciones entre el antes y el después aún son evidentes. La democracia sustancial y el Estado constitucional no están exentos de problemas y cuestionamientos. ¿Someter la participación a un poder institucionalizado, la Función de Participación Ciudadana y Control Social, es una forma que más controla que canaliza el poder popular y lo disciplina?, ¿ existe una relación entre el autoritarismo y el Estado constitucional, interventor y contraparlamentario?, ¿la sustancialidad constitucional no es una forma sellar la historia?, ¿ someter los conflictos políticos a un organismo de control jurisdiccional elitiza salidas políticamente fáciles y sin debate político y social? Lo que he intentado demostrar en este ensayo es que el neoconstitucionalismo a la ecuatoriana, cuyos pilares fueron la democracia sustancial y el Estado constitucional, de inspiración ferrajoliana, fue el discurso estructurador que le dio coherencia argumentativa al texto constitucional desde la materialización de la teoría en normas jurídicas constitucionales (semántica); al tiempo que permitió la formación de un espacio de equilibrio para la deliberación democrática en el proceso constituyente, que viabilizó la toma de opciones ideológicas estructurales (pragmática); y, que pone a disposición una oportunidad histórica para la instrumentación de la Constitución de 2008 para la transformación social y la legitimidad material de los derechos y el sistema político en las sociedades latinoamericanas, como un mecanismo social que cree nueva teoría y la transforme permanentemente en compromiso político por las/os más débiles y por nuevas opciones de insurgencia política y jurídica (sintáctica).

Además, en este trabajo he intentado demostrar que el plan teórico de Principia iuris, obra magistral del maestro Luigi Ferrrajoli, si bien es cierto es una teoría normativa, sirve como método de análisis del uso de la teoría, para el caso del neoconstitucionalismo, en un proceso social determinado, en el caso de este ensayo, el proceso constituyente para la elaboración de la Constitución de 2008 del Ecuador. Mi percepción no es exclusiva, de acuerdo a lo que hace notar Prieto Sanchís: Principia iuris no es sólo una teoría del Derecho para el Estado constitucional; sus conceptos más generales y elementales presentan un alcance más amplio, válido para explicar sistemas jurídicos precedentes e incluso sistemas normativos no jurídicos. ${ }^{92}$

Así, si para Ferrajoli, la positividad es un rasgo propio del derecho moderno en tanto estructura histórico-institucional; también, lo es, a partir de lo establecido en este ensayo, su instrumentalidad política con carácter emancipador ante un Derecho socialmente vaciado en América Latina. ${ }^{93}$ Quiero demostrar que nuestro proceso constituyente no se nutrió de simples trasplantes jurídicos, pero que sí tuvo un hilo estructurador que hace posible la coexistencia varios intereses y discursos, tanto teóricos como prácticos en el texto constitucional.

También, he buscado mostrar, desde mi perspectiva, lo indispensable que resulta relacionar la teoría y la actuación de las/los intelectuales en los procesos sociales de lucha, mientras que ésta debe guiarlas hacia la transformación social y la apropiación del sistema político-

\footnotetext{
92 PRIETO SANCHÍS, Luis, "Principia iuris: una teoría del derecho no (neo)constitucionalista para el Estado constitucional”, Op. Cit. nota 36, p. 326.

93 ÁVILA LINZÁN, Luis Fernando, "La pluralidad de sistemas jurídicos frente a la invisibilidad de los social en el derecho latinoamericano", en: Enzo Bello y otros (eds.), Dereito y Marxismo. Tendencias atuais, Universidade de Caxías, Brasil, 2012.
} 
jurídico como arma de la revolución, ${ }^{94}$ para nuestro caso, constitucional. Pues las/los intelectuales ante el poder tienen dos opciones: o se dejan instrumental por él o lo toman para sí para transformar el mundo. ${ }^{95}$ Nuestra Constitución es un campo de batalla abierto para luchar contra el poder las clases dominantes. Hace un par años escribí con Alex Valle un ensayo introductorio que se tituló "¿Derecho de la miseria o miseria del Derecho?, como parte del libro colectivo que edité bajo el título de Emancipación y Transformación Constitucional, ${ }^{96}$ el cual fue reeditado dentro del libro colectivo Marxismo y Dereito por la Universidad de Caxías Do Sul en Brasil. ${ }^{97}$ En este ensayo lo que intentábamos era describir los elementos centrales de lo que sería una teoría crítica para América Latina. Con este fin hacíamos un análisis estructural de las corrientes más importantes en la Región, separándolas de las visiones conservadoras que no consideran integrada la política al derecho bajo el supuesto de una neutralidad política que es cuestionable desde el simple sentido común. Diferenciábamos dos ejes centrales de esta propuesta de teoría crítica: el horizonte posible de la crítica y el horizonte necesario de la crítica. Por esto la metáfora adaptada de Marx en su crítica a Proudhon: ¿Filosofía de la miseria o miseria de la filosofía? Es decir, ¿Derecho de la miseria o miseria del derecho?

El horizonte posible se refiere a las corrientes progresistas que en la región operan sobre las estructuras, pero sin reemplazarlas. Reconocemos esta corriente como válida, pero insuficiente. Es legítima como referente jurídica de cambio en la transición política. Luego, el horizonte necesario plantea la necesidad de ir más allá. Bajo esta perspectiva, el nuevo constitucionalismo latinoamericano que se enfoca en los nuevos constructos desde el Sur y que proponen un giro epistémico contrahegemónico y contracivilizatorio, tales como la naturaleza como sujeta de derechos, la participación social, el sumak kwasay (buen vivir), la interculturalidad, y los derechos colectivos; fija un camino hacia la transformación social y la sustitución de las estructuras de la exclusión en la América Latina del siglo XXI.

La propuesta de Ferrajoli sobre el garantismo y el Estado constitucional, la democracia sustancial y las garantías, constituye un puente entre estos dos horizontes en nuestra región, de allí su validez social, jurídica, histórica y política. Y, de allí, la necesidad de estudiarla e instrumentarla para lo que sea útil a las luchas y emancipación de nuestros pueblos. Finalmente, el pensamiento de nuestro comentado maestro pudiera ser un mito, pero no como negación o mentira, sino como lo percibiera Gramsci, un impulso movilizador de transformaciones y lucha contra el poder de las élites y la geopolítica del imperialismo. ${ }^{98}$

\footnotetext{
${ }^{94}$ Véanse: GRAMSCI, Antonio, Introducción a la Filosofía de la Praxis, Editorial Península, Barcelona, 1972; Althusser, Louis y Étienne Balibar, "La Filosofía: arma de la revolución", en: Althusser, Louis, Para Leer el Capital, Siglo XXI editores, México, 2006.

95 Véase: FOUCAULT, Michel y DELEUZE, Gilles, Un diálogo sobre el poder y otras conversaciones, Madrid, Alianza Editorial, 1992.

${ }^{96}$ ÁVILA LINZÁN, Luis Fernando y VALLE, Alex, "Derecho de la miseria o miseria del derecho", en: Luis Fernando Ávila Linzán (ed.), Emancipación y Transformación Constitucional, Corte Constitucional, 2011.

${ }^{97} \mathrm{Idem}$.

98 GRAMSCI, Antonio, Notas sobre Maquiavelo sobre la política y sobre el Estado moderno, Buenos Aires, Nueva Visión, 2008.
} 
FUENTES

BIBLIOGRÁFICAS

ABRAMÓVICH, Víctor, Acceso a la justicia como garantía de los derechos económicos, sociales y culturales. Estudio fijado por la Corte Interamericana de Derechos Humanos, Costa Rica, Corte Interamericana de Derechos Humanos, 2007.

ACOSTA, Alberto y otros, La América que queremos: 32 ensayos en defensa de la vida, Tierramérica, 1998,

ACOSTA, Alberto, Bitácora constituyente: ¡Todo para la patria, nada para nosotros!, Quito, Abya-Yala, 2008.

, El desarrollo en la globalización: el reto de América Latina, Caracas, ILDIS, Nueva Sociedad, 2000.

, "El Estado plurinacional, puerta para una sociedad democrática: a manera de prólogo", en Acosta, Alberto, comp., Plurinacionalidad: democracia en la diversidad, Quito: ABYA YALA, 2009.

"La Constitución de Montecrisiti, medio y fin para cambios estructurales", en Nuevas instituciones del derecho constitucional ecuatoriano, Quito, INREDH, 2009.

"La cruzada contra el estado: una corriente indetenible", en Fundación José Peralta, Reforma del Estado: propuesta popular, Encuentro: por una propuesta popular sobre reforma del estado, Quito, 1993.

, "Representación, participación y democracia”, en Instituto Latinoamericano de Investigaciones Sociales, ILDIS, La innovación partidista de las izquierdas en América Latina, Quito, ILDIS, Fundación Friedrich Ebert, 2008.

, "Siempre más democracia, nunca menos: a manera de prólogo", en Acosta, Alberto, comp., El Buen Vivir: una vía para el desarrollo, Quito: Abya-Yala, 2009.

, "Una propuesta alternativa de política y reforma estructural, Ecuador.

Congreso Nacional, en coord.; Ecuador: crisis, reactivación, descentralización y cambio de modelo económico, Quito, Congreso Nacional, 1999.

ALTHUSSER, Louis y ÉTIENNE Balibar, “La Filosofía: arma de la revolución”, en Althusser, Louis, Para Leer el Capital, Siglo XXI editores, México, 2006.

ANDRADE, Pablo, "Negociando el cambio: Fuerzas Políticas en la Asamblea Constituyente ecuatoriana de 1998", Pablo Andrade y otros, en Estructura Constitucional en el Estado Constitucional, Quito, Universidad Andina Simón Bolívar, Fundación Centro de Estudios Políticos y Sociales y otros, 2004.

ANZALDÚA, Gloria, "Movimientos de rebeldía y la cultura que traiciona”, en Otras Inapropiables, Creative Commons, California, USA, 2004.

ÁVILA LINZÁN, Luis Fernando, Emancipación y Transformación Constitucional, Corte Constitucional, 2011. 
"El acceso a la justicia y la emancipación social de las personas excluidas”, en Ramiro Ávila, ed., Neoconstitucionalismo y sociedad, Ministerio de Justicia y Derechos Humanos, Quito. ríodo de transición, 2011.

, Política, Justicia y Constitución, Quito, Corte Constitucional para el pePolítica de reforma constitucional por vía de consulta popular en Ecuador: ¿ingenuidad, sinceramiento o estrategia?”, en revista Rebelión (virtual): www. rebelion.ogr, 2011.

"La Constitucionalización de la Administración de Justicia", en Ramiro Ávila, ed., La Constitución del 2008 en el contexto andino. Análisis desde la doctrina y el derecho comparado, Ministerio de Justicia y Derechos Humanos, Quito, 2008.

La pluralidad de sistemas jurídicos frente a la invisibilidad de los social en el derecho latinoamericano", en Enzo Bello y otros, Dereito y Marxismo. Tendencias atuais, Universidade de Caxías, Brasil, 2012.

"Legtimidad Social e Independencia Judicial Interna", en Luis Fernando Ávila Linzán, ed., La Transformación de la Justicia, Ministerio de Justicia y Derechos Humanos, Quito, 2008.

ÁVILA LINZÁN, y VALLE, Alex, “¿Derecho de la miseria o miseria del Derecho?”, en Enzo Bello y otros, Dereito y Marxismo. Tendencias atuais, Universidade de Caxías, Brasil, 2012.

, "Derecho de la miseria o miseria del derecho", en Luis Fernando Ávila Linzán, Emancipación y Transformación Constitucional, Corte Constitucional, 2011.

ÁVILA SANTAMARÍA, Ramiro, "Estado Constitucional de Derechos y Justicia”, en Ramiro Ávila, ed., La Constitución de 2008 en el Contexto Andino. Análisis desde la doctrina y el derecho comparado, Quito, Ministerio de Justicia, 2008.

, ed., Neoconstitucionalismo y Sociedad, Quito, Ministerio de Justicia y Derechos Humanos, 2008.

, "Neoconstitucionalismo Transformador. El estado y el derecho", en Alberto Acosta y Esperanza Martínez, comps., ABYA YALA, Quito, 2011.

, "El amparo constitucional: entre el diseño liberal y la práctica formal", en Un cambio ineludible: la Corte Constitucional, Tribunal Constitucional, Quito, 2008 .

ed., La Constitución del 2008 en el contexto andino. Análisis desde la doctrina y el derecho comparado, Quito, Ministerio de Justicia y Derechos Humanos, 2008.

ÁVILA SANTAMARÍA, GRIJALVA, Agustín, y MARTÍNEZ, Rubén, eds., Desafíos constitucionales La Constitución ecuatoriana del 2008 en perspectiva, Ministerio de Justicia y Derechos Humanos y Tribunal Constitucional, 2008.

BUTLER, Judith, Deshacer el Género, Editorial Paidós, Madrid, 2004. 
CARBONELL, Miguel, El neoconstitucionalismo en América Latina: elementos para una definición, México, Instituto de Investigación Jurídica-UNAM, 2008.

, (ed.), Neoconstitucionalismo(s), Madrid, Trotta, 2003.

, (ed.), Teoría del neoconstitucionalismo, Madrid, Trotta, UNAM, 2007.

, y Salazar Ugarte, Pedro (eds.), Garantismo: Estudios sobre el pensamiento

jurídico de Luigi Ferrajoli, Madrid, ES: UNAM. Centro de Investigaciones Jurídicas, Trotta, 2005.

CÁRCOVA, Carlos María, La Opacidad del Derecho, Madrid, Editorial Trotta, 1998.

Corporación Latinoamericana de Desarrollo (CLD), Memorias de eventos de Derecho Constitucional, Quito, CLD, 2001.

Corporación de Estudios para el Desarrollo (CORDES), comp., La ruta de la gobernabilidad, Quito, CORDES, 1999.

DONOSO, Juan Carlos, Base de datos cualitativa sobre Cultura Constitucional, Ecuador, Corte Constitucional, Proyecto SIMEC, diciembre 2012.

ECHEVERRÍA, Julio, “El Estado en la nueva Constitución”, en Santiago Andrade, Agustín Grijalva y Claudia Storini, La Nueva Constitución del Ecuador, Serie Estudios Jurídicos, Vol. 20, Quito, Corporación Editora Nacional y Universidad Andina Simón Bolívar, 2009.

FACIO y Lorena Fries, eds., Género y Derecho, Santiago de Chile, Ediciones LOM, 1999.

FACIO, Alda, "Metodología para el Análisis de Genero y Fenómeno Legal”, en Alda Facio y Lorena Fries, eds., Género y Derecho, Santiago de Chile, Ediciones LOM, 1999.

FOUCAULT, Michel y Deleuze, Gilles, Un diálogo sobre el poder y otras conversaciones, Madrid, Alianza Editorial, 1992.

FAUR, Leonor, “Género, Masculinidades y Políticas de Conciliación Familia-Trabajo”, en Revista Nómadas, No. 24, abril/2006, Instituto de Estudios Sociales Contemporáneos, Universidad Central, Bogotá, 2006.

Hacia otra teoría crítica del derecho, ed., Santiago, LOM Ediciones, $1999 \mathrm{~b}$.

FERRAJOLI, Luigi, "Expectativas y garantías: primeras tesis de una teoría axiomatizada del Derecho”, Doxa, núm. 20, 1997, pp. 235-278.

, "Derechos Fundamentales", en Antonio de Cabo y Gerardo Pisarello, eds., Los Fundamentos de los Derechos Fundamentales. Luigi Ferrajoli, Buenos Aires, Editorial Trotta, 2001.

, "Pasado y Futuro del Estado de Derecho", en Miguel Carbonel y Rodolfo Vásquez, coord., Estado Constitucional y Globalización, Porrúa UNAM, México, 2001.

, "Más Allá de la Soberanía y Ciudadanía: un constitucionalismo global", en Miguel Carbonel y Rodolfo Vásquez, coord., Estado Constitucional y Globalización, México, Porrúa UNAM, 2001. 
, Derechos y garantías: la ley del más débil, Madrid, Trotta, 2001.

, Derecho y Razón. Teoría del Garantismo Penal, Madrid, Editorial Trotta, 2001.

, "Doce Cuestiones en torno a Principia Iuris", en Revista Doxa, Cuadernos de Filosofía del Derecho, núm. 20, 1997, pp. 235-278.

drid, 2001.

, Los fundamentos de los derechos fundamentales, Editorial Trotta, Ma-

, Principia iuris. Teoría del Derecho y de la Democracia, tomo I: “Teoría del Derecho", Madrid, Editorial Trotta, 2011.

Principia iuris. Teoría del Derecho y de la Democracia, tomo II: “Teoría de la Democracia”, Madrid, Editorial Trotta, 2011.

, Principia iuris. Teoría del Derecho y de la Democracia, tomo II: "La sintaxis del derecho", Madrid, Editorial Trotta, 2011.

, "Doce cuestiones en torno a principia iuris", en Revista Cultura de la Legalidad, No.1 septiembre 2011-febrero 2012.

FRASER, Nancy, Iustitita Interrupta: reflexiones críticas desde la posición "postsocialista", Universidad de los Andes, Bogotá, 1997.

GARCÍA VILLEGAS, Mauricio, “Derechos sociales y necesidades políticas. La eficacia jurídica de los derechos sociales en el constitucionalismo colombiano", en Boventura De Sousa Santos, El caleidoscopio de las justicias en Colombia. Análisis socio-jurídico, T. I, Bogotá, Ediciones Uniandes, 2001.

GARGARELLA, Roberto, "Presentación”, en Desafíos constitucionales La Constitución ecuatoriana del 2008 en perspectiva, Ministerio de Justicia y Derechos Humanos y Tribunal Constitucional, 2008.

GRAMSCI, Antonio, Introducción a la Filosofía de la Praxis, Editorial Península, Barcelona, 1972

, Notas sobre Maquiavelo sobre la política y sobre el Estado moderno, Buenos Aires, Nueva Visión, 2008.

GRIJALVA, Agustín, “¿Una constituyente más?”, en Revista Renovación, entre voces, ¿Qué se juega en la segunda vuelta?, No. especial 4, Quito, nov-dic 2006.

"Acción Extraordinaria de Protección", en Claudia Escobar, Teoría Práctica de la Justicia Constitucional, Quito, Ministerio de Justicia y Derechos Humanos, 2010.

GRIJALVA, Agustín y Valle, Alex, Uso y funcionamiento de la justicia constitucional, Quito, Ministerio de Justicia y Derechos Humanos, 2010.

HÄBERLE, Peter, El estado constitucional, Lima, Universidad Nacional Autónoma de México, 2003. 
, Teoría de la constitución como ciencia de la cultura, Madrid, Tecnos, 2000.

HOOKS, Bell, "Mujeres Negras: dar forma a la teoría feminista", en Otras Inapropiables, Creative Commons, California, USA, 2004.

HURTADO, Osvaldo, introd., "Los nuevos límites del estado", en El problema del estado y su reforma en América Latina, Quito, CORDES, 1989.

, "El sistema político en el Ecuador", en Ayala Mora, Enrique, ed., Ensayos generales II: nación, estado y sistema político, Quito, Corporación Editora Nacional, 1990.

, El poder político en el Ecuador, Quito, Planeta, Letraviva, 1993.

, Gobernabilidad y reforma constitucional, Quito, Corporacion Editora Nacional, Libros de bolsillo; vol. 8, 1993.

, "Gobernabilidad, democracia y pobreza", en Zevallos, José Vicente, ed., Estrategias para reducir la pobreza en América Latina y el Caribe, Quito, PNUD, 1997.

, Una constitución para el futuro, Quito, Fundación Ecuatoriana de Estudios Sociales, FESO, 1998.

JARAMILLO, Isabel Cristina, "La Crítica Feminista al Derecho, estudio preliminar", en Robin West, Género y Teoría del Derecho, Bogotá, Siglo de Hombres editores, Facultad de Derecho de la Universidad de Los Andes, Ediciones Uniandes, Instituto Pensar, 2000.

KELSEN, Hans, ¿Quién debe ser el defensor de la Constitución?, Madrid, Editorial Tecnos, 2002.

LASALLE, Ferdinand, ¿Qué es una Constitución?, Barcelona, Editorial Ariel, 1989.

LEMAITRE, Julieta, “¿Puede la Corte Constitucional emancipar a las mujeres?”, en Universidad de Los Andes, Facultad de Derecho, Observatorio de Justicia Constitucional, 2000 .

MELMAN, Charles, Lo ingobernable en la sociedad, Corporación de Estudios para el Desarrollo; Ecuador: un problema de gobernabilidad, Seminario "Ecuador: un problema de gobernabilidad” / Quito, Quito, CORDES, 1996.

MORA SIFUENTES, Francisco M., "El Garantismo como constitucionalismo de reglas. (Apuntes sobre las normas en Principia iuris", Cuadernos Electrónicos de Filosofía del Derecho, núm. 26, 2012.

MOUFFE, Chantal, En torno a lo político, Fondo de Cultura Económica, Buenos Aires, 2007.

OYARTE, Rafael, "Relaciones Ejecutivo-Legislativo", en Santiago Andrade, Agustín Grijalva y Claudia Storini, La Nueva Constitución del Ecuador, Serie Estudios Jurídicos, Vol. 20, Quito, Corporación Editora Nacional y Universidad Andina Simón Bolívar, 2009. 
PISARELLO, Gerardo, Un largo Termidor: historia y crítica del constitucionalismo antidemocrático, Quito, Corte Constitucional para el Período de Transición, 2011.

PRIETO SANCHÍS, Luis, "Principia iuris: una teoría del derecho no (neo)constitucionalista para el Estado constitucional”, Doxa, núm. 31, 2008, pp. 325-354.

RENTERÍA, Adrian, "Justicia Constitucional y la Esfera de lo indecible en Luigi Ferrajoli”, en Revista Isonomía, oct-2003.

SALGADO PEÑAHERRERA, Germánico, "El estado ecuatoriano: crisis económica y estado desarrollista", en Hurtado, Osvaldo, introd. ; Los nuevos límites del estado, Quito, CORDES, 1989.

SALGADO, Hernán, Manual de Justicia Constitucional Ecuatoriana, Serie Fortalecimiento de la Justicia Constitucional en el Ecuador, Corporación Editora Nacional, Quito, 2004 .

SANTOS, Boaventura De Sousa, "Derecho y Democracia. La reforma global de la justicia”, en Boaventura De Souza Santos y García Villegas, comps., El Caleidoscopio de las Justicias en Colombia. Análisis Socio-Jurídico, Tomo I, Bogotá, Siglo del Hombre Editores, 2001.

, "Las paradojas de nuestro tiempo y la plurinacional", en Acosta, Alberto, comp., Plurinacionalidad: democracia en la diversidad, Quito, ABYA YALA, 2009.

"Los Paisajes de la Justicia en las Sociedades Contemporáneas", en Boaventura de Sousa Santos y Mauricio García Villegas, El caleidoscopio de las Justicias en Colombia. Análisis socio-jurídico, Tomo I, Bogotá, Panamerica Formas, 1ra. reimpresión, 2004.

De la Mano de Alicia. Lo social y lo político en la postmodernidad, Bogotá, Ediciones Uniandes, 2001.

SARTORI, Giovanni, ¿Qué es la democracia?, México, Nueva Imagen, 1997. Elementos de Teoría Política, Madrid, Alianza, 1999. Partidos y sistemas de partidos, Madrid, Alianza, 1999.

SCHMITT, Karl, La Defensa de la Constitución, Madrid, Editorial Tecnos, 1998.

SCHUMPETER, Joseph A., Capitalismo, Socialismo y Democracia, Barcelona, ediciones Folio, 1986.

TIGAR, Michael y LEVY, Madelaine, 1973, “La Jurisprudencia Insurgente”, en José maría martinelli, comp., Lecturas sobre Derecho y Derecho Económico, Universidad Autónoma Metropolitana- Iztapala, México.

TORRES, Luis Fernando, “¿Cómo cambió el Ecuador entre el 2007 y el 2009?, en Luis Fernando Torres, ed., Debate Constitucional. Monografías, Quito, Fundación Hans Seidel, 2010. 
Presidencialismo Constituyente. Un camino hacia el autoritarismo en el Ecuador, Quito, Cevallos Editora Jurídica, 2009.

TRUJILLO VÁSQUEZ, Julio, ¿Actualidad o crisis del constitucionalismo social en el Ecuador?, Quito, Pontificia Universidad Católica del Ecuador, 1977.

"El Estado en la Constitución", en Viciano, Roberto, ed., Estudios sobre la constitución ecuatoriana de 1998, Valencia, CEPS, Universidad Andina Simón Bolívar, Sede Ecuador, 2005.

Teoría del estado en el Ecuador: estudio de derecho constitucional, Quito, Universidad Andina, 2006.

UPRIMNY, Rodrigo, "Las transformaciones de la administración de justicia en Colombia", en Boventura De Sousa Santos, El caleidoscopio de las justicias en Colombia. Análisis socio-jurídico, T. I, Bogotá, Ediciones Uniandes, 2001.

VICIANO, Roberto y MARTÍNEZ, Rubén, “Aspectos Generales del Nuevo Constitucionalismo Latinoamericano”, en Ávila Linzán, Luis Fernando, Política, Justicia y Constitución, Quito, Corte Constitucional para el período de transición, 2011.

West, Robin, Género y Teoría del Derecho, Bogotá, Siglo de Hombres editores, Facultad de Derecho de la Universidad de Los Andes, Ediciones Uniandes, Instituto Pensar, 2000.

WILLS, Maria, “Mujeres y Cuotas Políticas en los Países Andinos”, en Nadando contra Corriente, Magdalena León ed., UNIFEM y otros, Quito, 2005.

ZAIDÁN, Salim, “¿Neoconstitucionalismo en el Ecuador?”, en Maldonado Muñoz, Mauricio, ed., Revista Ruptura No. 54, Quito, 2011.

, "Peligros del empoderamiento del juez en el esquema neoconstitucional ecuatoriano", Torres, Luis Fernando, ed.; Debate constitucional con jurisprudencia, Quito, EC: Jurídica Cevallos, 2012a.

, Neoconstitucionalismo: teoría y práctica en el Ecuador, Quito, EC: Jurídica Cevallos, 2012.

NORMATIVA JURÍDICA

Constitución del Ecuador, RO 449: 20-oct-2008. 
